Article

\title{
Investigation of Micro Gas Turbine Systems for High Speed Long Loiter Tactical Unmanned Air Systems
}

\author{
James Large ${ }^{1,+}$, Apostolos Pesyridis ${ }^{1,+}$ \\ 1 College of Engineering and Design, Brunel University London, Uxbridge UB8 3PH, London, UK \\ * Correspondence: a.pesyridis@brunel.ac.uk; Tel.: +441895267901 \\ + These authors contributed equally to this work.
}

\begin{abstract}
In this study, the on-going research into the improvement of micro-gas turbine propulsion system performance and the suitability for application as propulsion systems for small tactical UAVs $(<600 \mathrm{~kg})$ is investigated. The study is focused around the concept of converting existing micro turbojet engines to turbofan with the use of a continuously variable gearbox, thus maintaining a single spool configuration and relative design simplicity. This is an effort to reduce the initial engine development cost, whilst improving propulsive performance. The BMT 120 KS micro turbojet engine is selected for performance evaluation of the conversion process using gas turbine performance software, GasTurb13. The preliminary design of a matched low-pressure compressor (LPC) for the proposed engine is then performed using meanline calculation methods. According to the analysis carried out, an improvement in the converted micro gas turbine engine performance in terms of thrust and specific fuel consumption is achieved. Furthermore, with the introduction of a CVT gearbox, fan speed operation may be adjusted independently of the core, allowing increased thrust generation or better fuel consumption. Therefore, enabling a wider gamut of operating conditions and enhances the performance and scope of tactical UAV.
\end{abstract}

Keywords: Unmanned Air Vehicles; Micro Gas Turbine Performance; Low Pressure Compressor Preliminary Design

\section{Introduction}

Many of today's Unmanned Air Vehicles (UAV's) are still propeller driven with the intention for low speed, low endurance applications. The use of advanced gas turbine propulsion systems enables faster flight speeds with increased efficiency, however are only found in larger military medium-altitude long endurance (MALE) and high-altitude long endurance (HALE) UAVs. This architecture of UAV commonly utilise existing turbine engines leveraged from small light aircraft to perform the role of command, control, communications, computers, intelligence, surveillance, and reconnaissance (C4ISR). As on-going operational requirements expand, there is a need for a smaller UAVs with increased mission profile capabilities in terms of speed and endurance.

Micro gas turbine engines (MTE) commonly classified under $1 \mathrm{kN}$ thrust of different configuration such as; turbojet, turboprop and turbofan provide a potential solution to achieving this requirement. The turbojet is the most common configuration of MTE found currently, mostly due to the relative simplicity of manufacture for homebuilders and hobbyists. These systems provide the required thrust for high-speed UAV applications, however like the larger architecture; the range is hindered by relatively poor fuel consumption. This is noted in works of both [1] and [2] that propose the conversion of micro-turbojets to micro-turbofan engines, and whom on-going projects provide the foundation of this study.

The primary objective of this paper is to investigate the potential of improving the performance of existing micro turbojet gas turbine engines through conversion to turbofan for applications in small tactical military UAVs for enhanced speed and endurance applications. However, the single biggest question that must be answered to validate the need to study methods of improving the performance of MTE's: "Is there a requirement for small UAVs and their respective mission profiles to utilise the 
potential advantages MTE's offer over current propulsion systems." In order to accomplish this, an innovative concept of conversion of existing micro turbojet to turbofan to minimise design time and cost is further explored. A suitable existing micro-turbojet engine is selected and evaluated using gas turbine performance software to study the advantages of conversion to turbofan. The preliminary design of the low-pressure compressor to be coupled to the existing turbojet is then performed for validation of gas turbine performance with CFD. The work conducted will also demonstrate the potential advantages of not designing a new engine from the beginning. To achieve these aims, the following objectives were set out:

- Market analysis for military UAV requirements to assist in the investigation of the feasibility of MTE propulsive methods for high speed, high endurance UAV applications and microturbine engines

- Technology study of current micro gas turbine engines and down selection of suitable turbojet MTE's to evaluate for turbofan conversion.

- Gas turbine engine performance study with the aid of GasTurb software to evaluate and analyse the performance improvements of proposed converted turbofan

- To perform preliminary aerodynamic design study for the low-pressure compressor to be coupled with the selected engine.

\section{Methodology}

\subsection{Unmanned Air Vehicles}

Unmanned air vehicles (UAVs) have been implemented in both military and civil applications for many years and the usage has exponentially increased within the last 10 years. With the advent of faster microprocessors enabling greater connectivity and better technologies to support intelligent autonomous control of unmanned air vehicles, this trend is likely to continue for the foreseeable future.

Pivotal in the operation of these unmanned air systems is a reliable and certifiable propulsion system which must meet the requirements for both civil \& military mission profiles and that must be sized for UAVs with take-off weights ranging from less than $150 \mathrm{~kg}$ to more than $600 \mathrm{~kg}$. Currently, gas turbine systems for UAV propulsion is of greater interest for military applications to gain greater tactical advantage and critically assist with saving the lives of soldiers. However, it is envisioned that the commercial use of gas turbine-propelled UAVs will eventually eclipse military use with a more cost-effective, reliable and efficient system. Thus, it was determined for this study, that focus is given to the military applications of gas turbine propulsion systems for UAVs below the $1 \mathrm{kN}$ requirement.

In the UK, the Military Aviation Authority (MAA) regulates the operation of both militaries manned, unmanned and remotely piloted aircraft through a series of regulatory articles. Table 1 shows the MAA classification categories together with their NATO equivalent taken from [3]. It should be noted that in the UK the common taxonomy for UAV classification applies to the commercial sector as well.

Table 1. NATO and UK unmanned aircraft classification.

\begin{tabular}{|c|c|c|c|c|}
\hline $\begin{array}{c}\text { Maximum } \\
\text { take-off weight } \\
\text { (MTOW) }\end{array}$ & NATO class & $\begin{array}{l}\text { Common } \\
\text { taxonomy }\end{array}$ & $\begin{array}{c}\text { MAA } \\
\text { category }\end{array}$ & $\begin{array}{c}\text { Representative } \\
\text { UAVs }\end{array}$ \\
\hline$<200 \mathrm{~g}$ & \multirow{4}{*}{$\begin{array}{c}\text { Class I }<150 \\
\mathrm{~kg}\end{array}$} & Nano & Class I (a) & Black Hornet \\
\hline & & Micro $<2 \mathrm{~kg}$ & \multirow{2}{*}{$\begin{array}{l}\text { Class I (b) } \\
\text { Class I (c) }\end{array}$} & \multirow{2}{*}{$\begin{array}{c}\text { Desert Hawk } \\
\text { III }\end{array}$} \\
\hline $200 g-20 \wedge \mathrm{g}$ & & Mini $2-20 \mathrm{~kg}$ & & \\
\hline $20-150 \mathrm{~kg}$ & & Small $>20 \mathrm{~kg}$ & Class I (d) & ScanEagle \\
\hline
\end{tabular}




\begin{tabular}{|c|c|c|c|c|}
\hline$>150 \mathrm{~kg}$ & $\begin{array}{c}\text { Class II } 150- \\
600 \mathrm{~kg}\end{array}$ & Tactical $>150 \mathrm{~kg}$ & Class II & Watchkeeper \\
\hline$>600 \mathrm{~kg}$ & $\begin{array}{c}\text { Class III }>600 \\
\mathrm{~kg}\end{array}$ & Male/Hale/Strike & Class III & MQ-9A Reaper \\
\hline
\end{tabular}

\subsection{Micro Gas Turbine Engines}

The thermodynamic operation of micro gas turbines of the same configuration (axial/radial) is in many respects similar to the larger turbomachines. However, the design procedure for MTE's is not a simple as applying scaling procedures to larger existing turbomachinery components. There are a number of operational and practical issues that affect the overall efficiency of MTEs and present a significant engineering challenge. According to [4] the main issues are; heat transfer, Reynolds number and geometric constraints.

- Significantly larger heat transfer between hot and cold components in micro turbomachinery which is often negligible in larger turbomachinery. The hightemperature gradient that exists between the compressor and combustion chamber leads to additional losses in the compressor efficiency unless significant thermal insulation is applied between components. In addition, this presents the issue of not being able to simply model the compressor as adiabatic during the design process, further increasing the technical challenge.

- The large difference in Reynolds number between large and micro gas turbines. The low Reynolds numbers is a large limiting factor in the efficiency of MTE's compressor stage and overall efficiency. Below the critical Re number for a single stage axial compressor, the rapid increase of drag occurs due to transition to laminar boundary flow.

- The relative surface roughness (surface roughness compared to the overall area) of components in MTE's is higher and thus are the skin friction losses. For a given Re number the losses due to skin friction increase as the component size decreases.

- Geometric restrictions in microturbine machinery from the manufacturing process and material properties.

The first use of micro gas turbine engines (MTE's) for UAV propulsion systems began with enthusiasts of aviation remote controlled (RC) models, however, are very rudimental in design and construction typically utilizing salvaged components such as the compressor in automotive turbochargers. Modern developments have yielded a new concept of the MTE, which intends to leverage the advantages of the system for smaller applications. Whilst no official category yet exists for MTE's, in line with the works of K. Kadosh and B. Cukurel, for this paper a micro gas turbine engine for propulsion is defined as producing a thrust under $1 \mathrm{kN}$ or $225 \mathrm{lbs}$. Currently, it is understood that whilst existing classes of gas turbine engines have shown great advancements in recent years, in terms of both efficiency and performance, the concept of MTE's remains relatively undeveloped. 


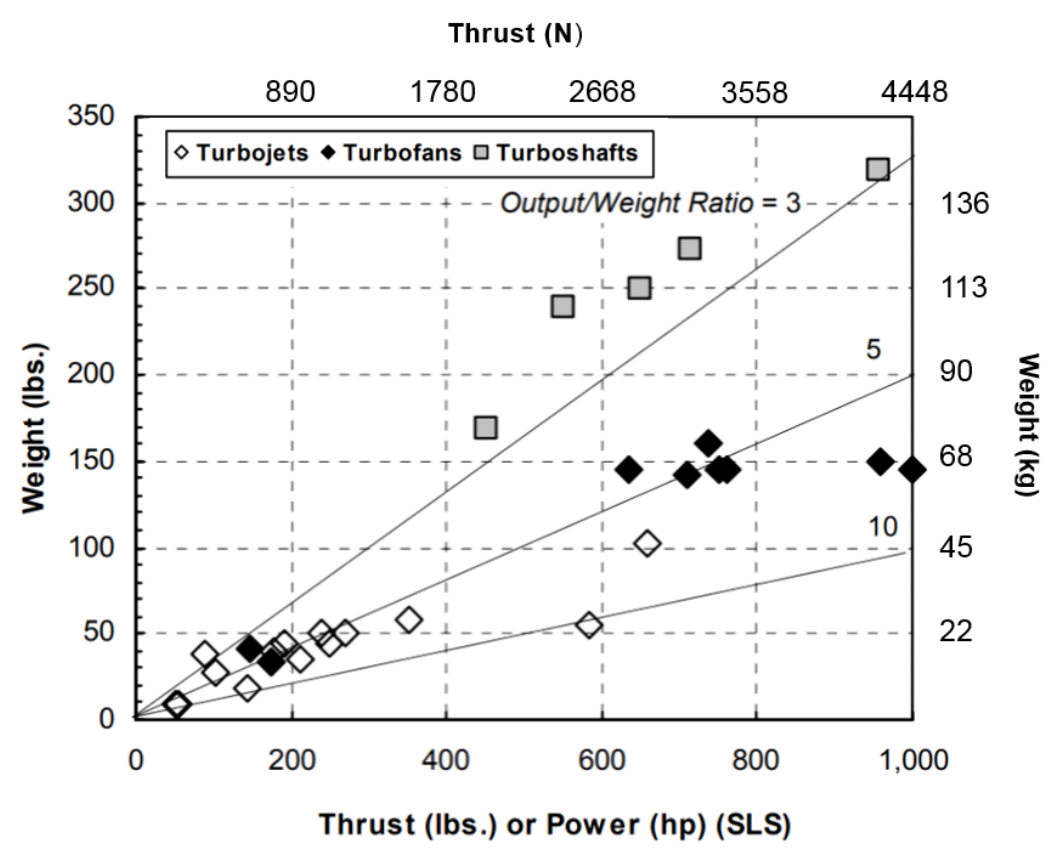

Figure 1. Existing gas turbine engines under $1000 \mathrm{lbs}$ of thrust.

It can be seen from Figure 1 above that the selection of engines in this thrust category consists mainly of turbojets, with a distinct lack of turbofan engines [5]. This observation forms the fundamental premises of this report, micro turbojet engines offer a simple design for producing high levels of thrust, however, suffer from poor efficiency and therefore increased specific fuel consumption. If an efficient, affordable turbofan engine of similar dimensions is successfully designed, the application of micro gas turbines may be expanded into further applications not considered due to the poor efficiency of currently available turbojets.

\subsection{Baseline Micro Turbojet Performance Study}

To further study the performance of turbojet to turbofan MTE conversions, a well-established engine platform is selected as a baseline. Due to the growing interest in MTE's over recent years and commercial/military industries protecting investments, it is increasingly difficult to source reliable analytical and numerical data of engines. From an extensive review of literature from related projects, the BMT 120 KS, Figure 2, engine is found to be the most promising candidate as a baseline turbojet platform to study the potential performance increase with conversion to turbofan. The improved performance of the BMT $120 \mathrm{KS}$ engine has been substantially researched over the years in particular at the Stellenbosch University's Department of Mechanical and Mechatronic Engineering, with the data and findings publicly made available through numerous academic papers.

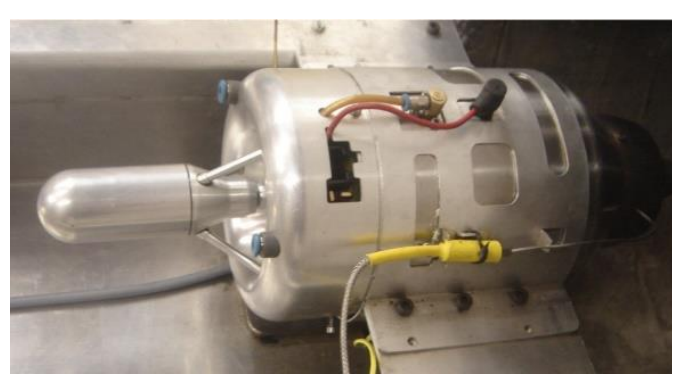

(a)

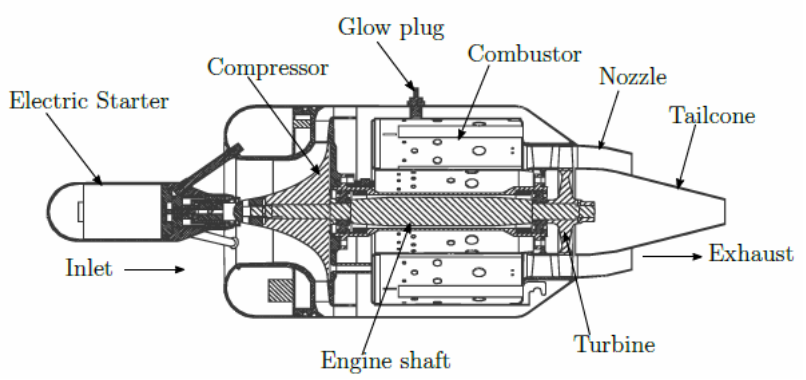

(b)

Figure 2. (a) Image of BMT $120 \mathrm{KS}$ micro jet engine [6]; (b) Schematic of BMT $120 \mathrm{KS}$ [7] 
The performance characteristics of an engine can be analyzed under two conditions, steady-state operation (equilibrium) or under transient operation. The scope of this study is under steady-state operation where the continuity of mass flow and conservation of energy are satisfied. In addition, engine performance is evaluated at the specified engine design point, off-design engine operation is to be conducted in further works.

For this study, the design point of the converted engine is at the point where the BMT operates at peak efficiency. This is at a nominal speed of 120,000 RPM with a thrust output of $130 \mathrm{~N}$. The thermodynamic cycle analysis and preliminary design of the proposed micro-turbofan engine are carried out in GasTurb 13 software. The program allows for the calculation of design and off-design performance parameters of the engine. With the use of parametric and optimization studies, the preliminary design of the turbofan conversion basic engine parameters and thermodynamic states may be determined.

Before the engine cycle analysis is discussed a quick note on the GasTurb software mathematics and iteration algorithms. Much like other commercial gas turbine simulation software GasTurb uses the matrix iteration method for convergence. This general iteration technique uses equal values of matching guesses and constraints, where guessed variables are continuously updated until the constraint parameters are satisfied. The iteration technique in GasTurb uses the multi-variable Newton-Raphson method to manipulate variables in a way that errors are insignificant. The system of linear equations is solved by means of the Gaussian elimination to generate the partial derivatives and find solutions. The process of the matrix iteration method is as follows:

- Estimate or matching guess of initial inlet temperatures for the compressor and turbine

- Calculation or matching constraint of the turbine and nozzle operating points.

- $\quad$ Calculate the error between matching constraints and guess.

- $\quad$ Adjust in the matching guesses and iterate.

- Combine the errors from the matching guess and constraints to form a matrix of partial derivatives.

- Invert the matrix and change all matching guesses by the amounts given by multiplying the inverted partial derivatives matrix by the error's matrix.

- $\quad$ Repeat the procedure until the errors between calculated values of the matching constraints and guesses converge.

The first step is to model the BMT $120 \mathrm{KS}$ micro turbojet engine, which is intended to be the core stream of the converted turbofan configuration. The purpose of this step is to validate the GasTurb simulation against experimental data from [6] and [8] as seen in Table 2 and 3

Table 2. BMT 120 KS Experimental engine performance data, taken from [8]

\begin{tabular}{|c|c|c|}
\hline Parameter & Experiment 1 & Experiment 2 \\
\hline Thrust $(\mathrm{N})$ & 127 & 137 \\
\hline Exhaust Gas Temperature $(\mathrm{K})$ & 1051 & 986 \\
\hline Specific fuel consumption $(\mathrm{g} / \mathrm{kNs})$ & 41.7 & 45.9 \\
\hline
\end{tabular}

Table 3. Summarized experimental data for BMT $120 \mathrm{KS}$, taken from [6]

\begin{tabular}{|c|c|c|c|}
\hline $\begin{array}{c}\text { Speed } \\
(\mathbf{R P M})\end{array}$ & Thrust (N) & $\begin{array}{c}\text { Mass Flow } \\
\mathbf{( k g / s )}\end{array}$ & Fuel Flow (kg/s) \\
\hline 120,000 & 136.6 & 0.293 & 0.0063 \\
\hline 100,000 & 78.4 & 0.233 & 0.0041 \\
\hline 80,000 & 43.4 & 0.175 & 0.0029 \\
\hline
\end{tabular}


Figure 3 below shows the station numbering for the $120 \mathrm{KS}$ turbojet engine, the thermodynamic states of the flow at each of the stations is calculated in the simulation. Specifications for the baseline BMT $120 \mathrm{KS}$ are seen in Table 4.

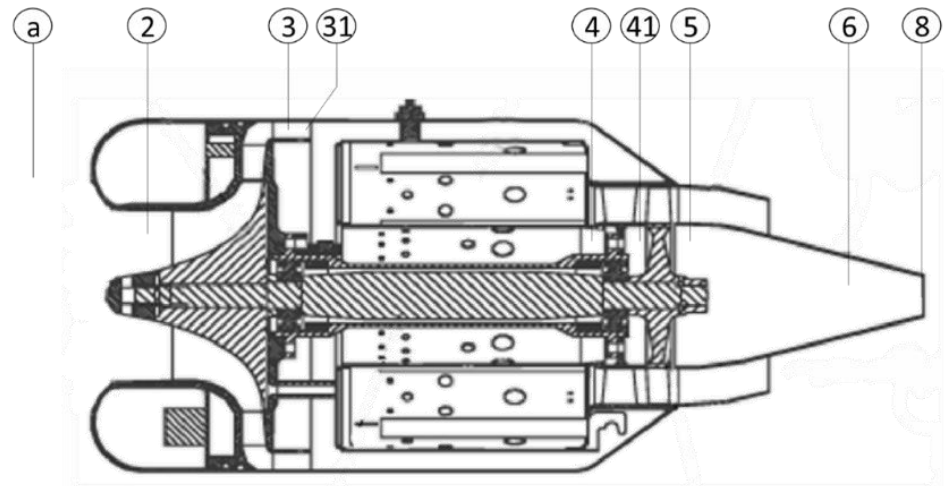

Figure 3. Baseline engine schematic with station numbering

Table 4. GasTurb13 Input Parameters for BMT 120 KS Engine

\begin{tabular}{|c|c|c|c|}
\hline Parameter & Name of Parameter & Value & Unit \\
\hline \multirow{3}{*}{ Ambient Conditions } & Total Temperature $\left(\mathrm{T}_{1}\right)$ & 288.15 & $\mathrm{~K}$ \\
\hline & Total Pressure $\left(\mathrm{P}_{1}\right)$ & 101.325 & $\mathrm{kPa}$ \\
\hline & Ambient Pressure $(\mathrm{Pa})$ & 101.325 & $\mathrm{kPa}$ \\
\hline \multirow{11}{*}{ Basic Engine Parameters } & Inlet Correct Mass Flow & 0.293 & $\mathrm{~kg} / \mathrm{s}$ \\
\hline & Fuel Flow Rate & 0.0063 & $\mathrm{Kg} / \mathrm{s}$ \\
\hline & Intake Pressure Ratio & 1 & \\
\hline & Compressor Pressure Ratio & 3.15 & \\
\hline & Burner Exit Temperature & 985 & $\mathrm{~K}$ \\
\hline & Fuel Heating Value & 43.124 & $\mathrm{MJ} / \mathrm{kg}$ \\
\hline & Burner Pressure Ratio & 0.89 & \\
\hline & Burner Pressure Drop & 0.11 & \\
\hline & Nominal Spool Speed & 120 & RPM (k) \\
\hline & $\begin{array}{c}\text { Turbine Exit Duct Pressure } \\
\text { Ratio }\end{array}$ & 1 & \\
\hline & Turbine Inlet Temperature & 1047 & $\mathrm{~K}$ \\
\hline \multirow{4}{*}{ Engine efficiency } & Mechanical Efficiency & 98 & $\%$ \\
\hline & $\begin{array}{c}\text { Isentropic Compressor } \\
\text { Efficiency }\end{array}$ & 81 & $\%$ \\
\hline & Isentropic Turbine Efficiency & 85 & $\%$ \\
\hline & Combustion Efficiency & 90 & $\%$ \\
\hline
\end{tabular}

The mass flow rate through the compressor is known from experimental data provided by [9], the blue line in Figure 4 and Figure 5 shows extrapolation of the pressure ratio and compressor efficiency from compressor map for BMT $120 \mathrm{KS}$ engine [13]. Note units of corrected mass flow, $101.325 \mathrm{kPa}=1.01325 \mathrm{bar}$, thus for relative mass flow through the compressor at $\dot{m}_{3}=0.293$ :

$$
\text { Corrected Flow }=\frac{\dot{m} \sqrt{T_{0 a}}}{P_{0 a}}
$$




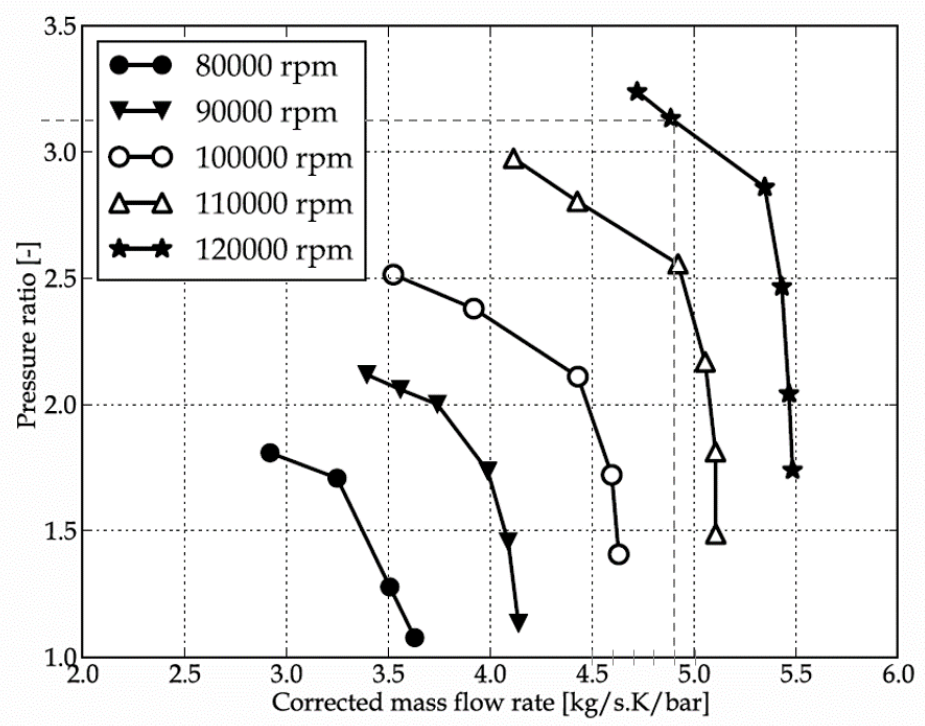

Figure 4. BMT compressor map (Pressure ratio vs Corrected mass flow).

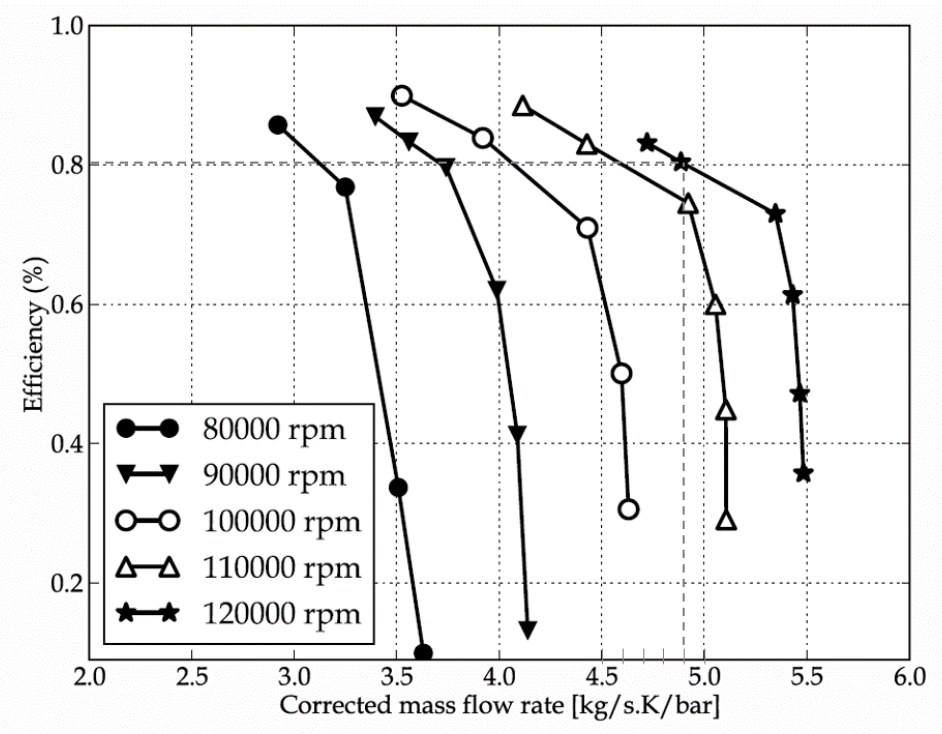

Figure 5. BMT compressor map (Efficiency vs Corrected mass flow).

Figure 6 below shows the input parameters for the baseline turbojet (BMT $120 \mathrm{KS}$ ) engine performance simulation, results for the simulation may be found in section 3 of this paper. 


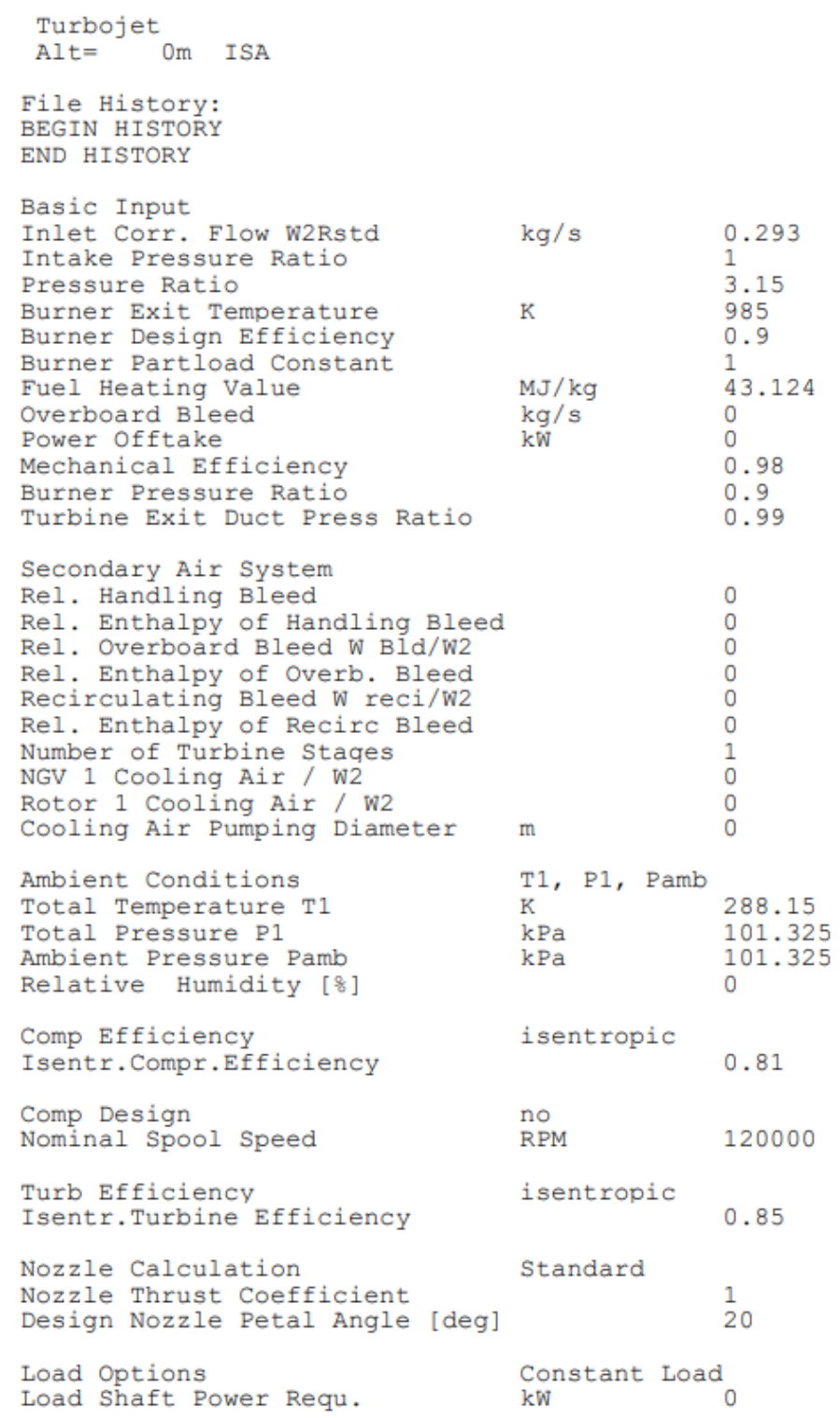

Figure 6. Baseline BMT 120 KS Turbojet Input Parameters to GasTurb 13 Software

\subsection{Micro Turbofan Conversion Performance Study}

With the core stream parameters simulated in GasTurb successfully validated against experimental data, the cycle analysis of the converted turbojet to turbofan is carried out. It should be noted that some challenges and limitations in the software were encountered which may affect the accuracy of the simulation. The software is used for simulation of most common types of aircraft and power generation gas turbines, however, the unique configuration that is to be modelled is not included. Limitations of software do not allow for new configurations of engine to be defined. A single spool turboshaft with a load fan attached is modelled, however does not account for thrust generation from bypass stream. Most suitable results are obtained from a single spool mixed turbofan engine configuration, where the CVT gearbox is accounted for via mechanical losses and the associated reduction in mechanical efficiency. Evaluation of variable gear ratios is obtained from multiple simulations. 


\subsubsection{Simulation Input Parameters}

Figure 7 below shows the station locations used for engine performance simulation of a turbofan engine.

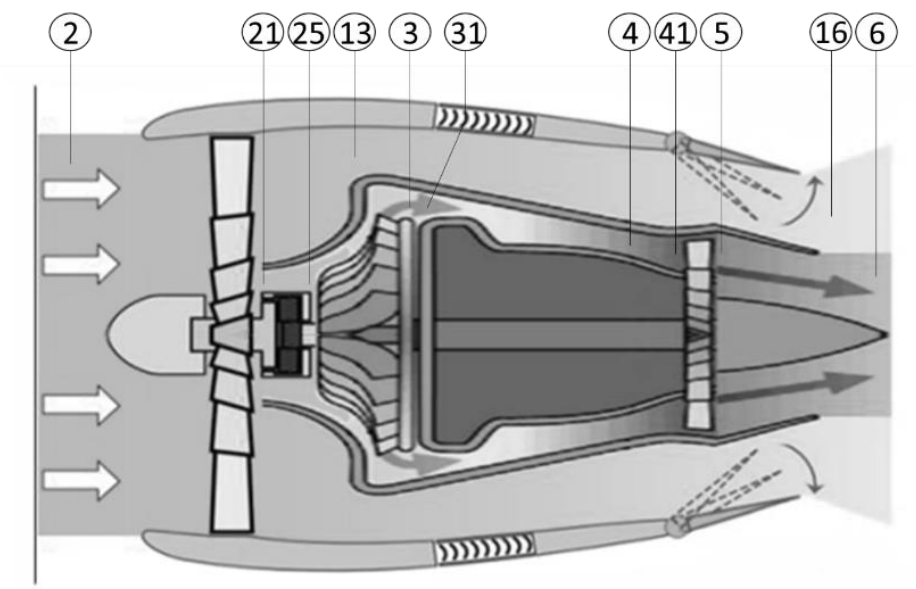

$$
\begin{aligned}
& 2 \text { - Inlet ambient, pre LPC } \\
& 21 \text { - After LPC, Inner } \\
& \text { Stream } \\
& 25 \text { - Pre HPC } \\
& 3 \text { - Post HPC } \\
& 31 \text { - Burner Entry } \\
& \text { 4-Burner }
\end{aligned}
$$

Figure 7. Converted turbofan engine schematic with associated station numbering

In conversion to turbofan, the BMT $120 \mathrm{KS}$ becomes the core of the engine, thus the known parameters for the validated baseline turbojet are transferred into the engine model. In a similar manner to the baseline turbojet, engine parameters are specified in the software. Figure 8 shows the finalized input parameters at a nominal fan speed of 30,492 RPM (after comprehensive iteration) used for the engine model. 


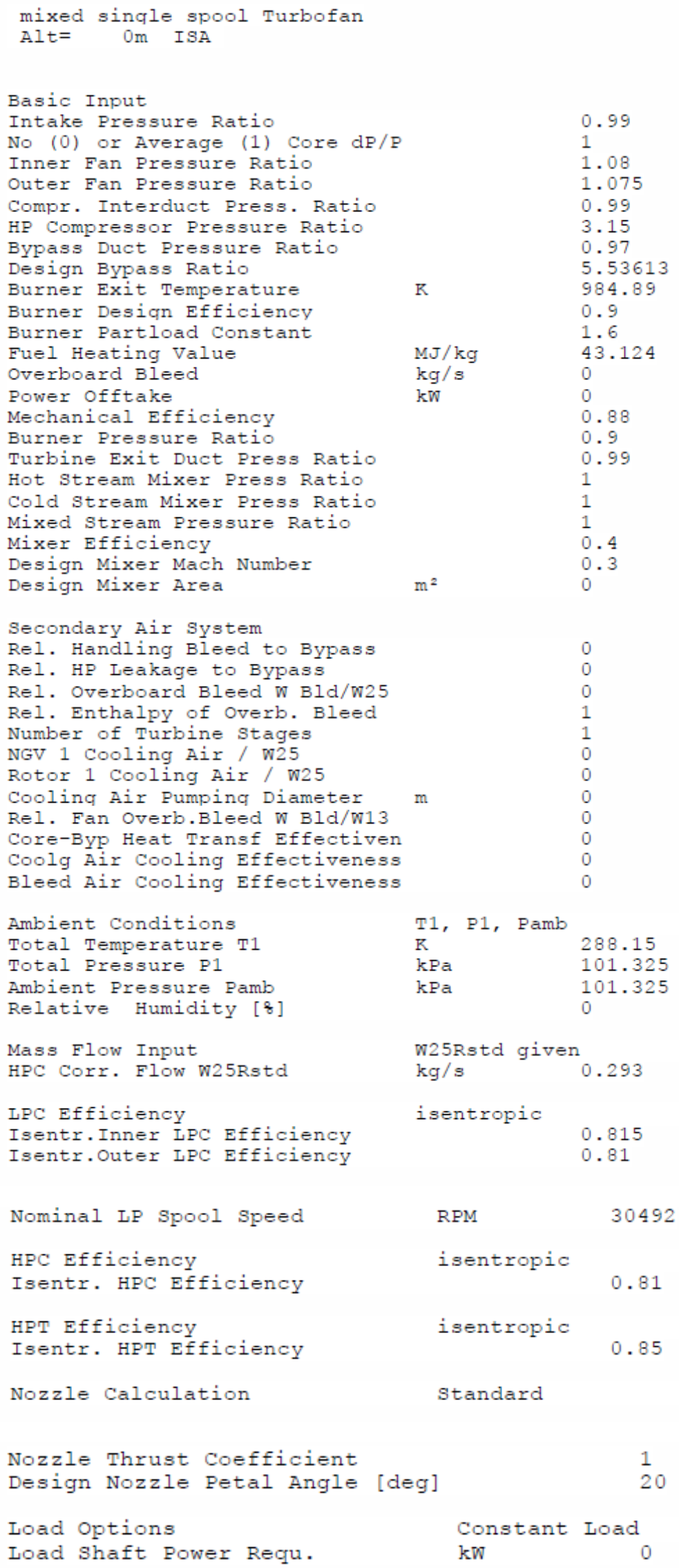

Figure 8. Basic input parameters for micro turbojet GasTurb engine model 
With reference to Figure 8, explanation of relevant input parameters may be found for the remainder of this section.

\subsubsection{Intake Pressure Ratio}

In GasTurb, many of the parameters may be specified in several ways which allows for flexibility in unknown parameters. For instance, the intake pressure ratio can be specified as any positive number is directly used as $\mathrm{P}_{2} / \mathrm{P}_{0}$ with the exception of the value 2 which selects the intake map option. However, no intake maps are currently available for micro gas turbines, moreover considering relative size and geometry, inlet compression is likely minimal and therefore total inlet pressure recovery is assumed thus the intake pressure ratio is set to 1 .

\subsubsection{Core Stream / Bypass Stream losses}

For turbofan engines a radial pressure profile at the engine face may be modelled. For the property (No (0) or Average (1) Core dP/P). For this simulation the value 0.99 is input, implying the negligible pressure loss difference in both the core and the bypass stream.

\subsubsection{LPC Pressure Ratio}

Fan intake maps for this application are not widely available. Use of similarity analysis and Buckingham $\mathrm{P}$ theorem to scale down the fan intake map from NASA's publicly available "Experimental Quiet Engine Program" was used [10]. The scaled fan map from results Fan A in the NASA publication seen in Figure 9 is used to determine the design point of the LPC for this study $[1]$.

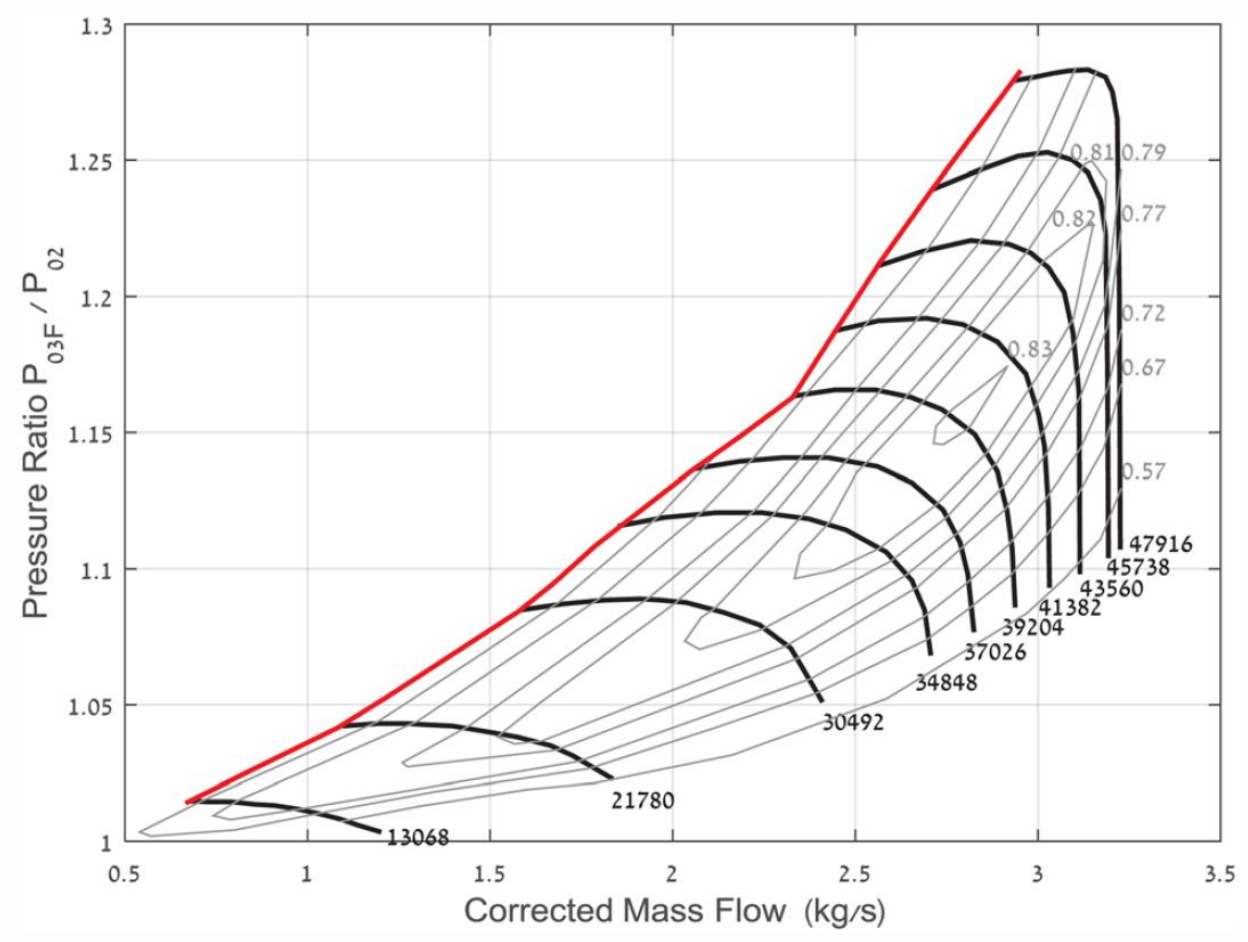

Figure 9. Scaled LPC fan performance map, [1]

The fan operation is studied at varying points along the performance curve in the figure above. Note that compressor is considered fully subsonic and that inlet Mach number are assumed at maximum 0.5 to prevent damage to LPC. Mass flow, pressure ratio and efficiency are read along the speed line for each of the compressor speeds. These values are then simulated to assess the LPC performance. The study is also conducted at varying compressor speeds. This is a representative study of the varying gear ratios of the coupled LPC. As mentioned, only the on-design operation is 
simulated in the model. For each of the corresponding speed lines, the associated corrected flow, pressure ratio and low-pressure compressor efficiencies are input to the engine model. The mechanical losses associated with the gearbox are also modelled via an increasing reduction in mechanical efficiency with a reduction in fan speed. As this engine model and simulation is only for the design point, the operating conditions of the core compressor and turbine performance maps are fixed at W25Rstd $0.293 \mathrm{~kg} / \mathrm{s}$ with P25/P3 $=3.15$ and thus results not affected by the single spool operating at the chosen nominal speed. As mentioned in previous sections, [2] state that a practical limit of the maximum core to bypass pressure ratio difference should not exceed a certain limit due to the increased axial velocity at rotor hub and therefore associated loading issues. It was found that at higher at speeds the difference between core and bypass pressure ratios exceed acceptable limits and result in unrealistic results. In addition, it is found that for the LPC, using the scaled performance map the maximum achievable speed is 30,432 . This is due to the compressor reaching the upper mass flow rate/pressure ratio achievable for the stage and results in core nozzle velocity dropping to unrealistic values.

\subsubsection{Duct Pressure Ratios}

Data is unavailable for duct pressure ratios in micro gas turbine applications. For the preliminary design, the pressure loss in flow ducts such as; bypass duct and turbine exit duct are assumed minimal and thus represented as 0.99 .

\subsubsection{Design Bypass Ratio}

The BPR is calculated during the iteration process of the simulation. The corrected mass flow inlet to high-pressure compressor is fixed and specified at W25Rstd $=0.293$. The fan mass flow or total inlet flow W2Rstd, is varied during the cycle analysis, determined from the fan map in Figure 9. BPR $=\mathrm{m} \_$dot fan $/ \mathrm{m} \_$dot core. With the pressure ratio across the LPC and efficiency also read from the performance curve the only remaining variable is the bypass ratio, which is iterated to satisfy the independent variables.

\subsubsection{Combustor Properties}

Input parameters for the burner are fixed to the validated values from the BMT $120 \mathrm{KS}$ turbojet engine simulation.

\subsubsection{Stream Mixing Parameters}

Inputs for hot and cold stream pressure ratio are set to 1 and not considered for the engine cycle analysis.

\subsubsection{Design Mach Numbers}

For the calculation of the thermodynamic cycle of the engine, flow properties such as the total pressure and temperature at component boundaries are only required. With the inclusion of appropriate design Mach numbers at component boundaries, aero-thermodynamic important dimensions and geometry are defined. In the case of this study, the dimensions of the core of the engine (turbojet to be modified) are known and therefore the definition of design Mach numbers is not required for all but the low-pressure compressor.

\subsubsection{Secondary Air System}

Similar to the baseline engine simulation, most secondary air systems are not defined for the engine performance system. Only the number of turbine stages is defined at 1 . 


\subsection{Low Pressure Compressor Preliminary Aerodynamic Design - Procedure}

This section covers the procedure used form the preliminary design of the low-pressure compressor to be matched with the BMT $120 \mathrm{KS}$ micro turbojet as part of the conversion to microturbofan. Performance parameters of the LPC determined in the previous section are carried over to the preliminary design. There are multiple design methods that may be applied in the field of turbomachinery. As the preliminary design of the low-pressure compressor (LPC) is not the sole topic of this paper, ANSYS turbomachinery design tools are utilized to make the iterative process of design more efficient. The advantage is that the design specifications and basic parameters determined from the engine performance section can be directly used to produce a preliminary design, rather than the more historic method of starting with existing machine flow path and geometry (which in this case would be difficult to acquire). The three basic steps for the design of the LPC are followed (reference Figure 10):

1. The design calculation scheme starts one-dimensional hypothesis of the mean streamline or socalled "mean-line design". Analysis of this stage provides estimations of the overall performance and efficiency of the LPC. Initial estimates on 1D aerodynamic dependent parameters are computed.

2. The next phase leads to the specification of the two-dimensional streamline. With the addition of blade geometry and by computing the blade as a succession of several cascades, the twodimensional nature of the flow is evaluated.

3. Finally, the blade profile is fully resolved by implementing a three-dimensional analysis with computational fluid dynamics.

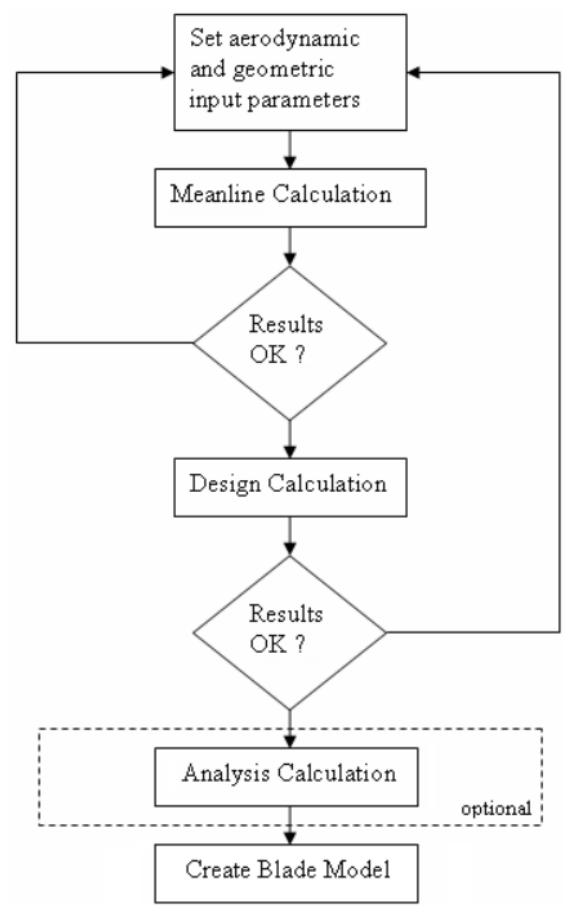

Figure 10. Flow chart of LPC aerodynamic design procedure

Preliminary aerodynamic design of the system is conducted using mean line flow through analysis. Vista, an ANSYS turbomachinery design tool extension by PCA Engineers Ltd is used to assist with the design process. The meanline flow-through design method is based on the conservation laws (mass, momentum and energy) upon which the basic flow physics are calculated along the critical streamline of the compressor. For the preliminary design of the LPC, evaluation of key performance parameters such as, DeHaller number, pressure rise coefficient, loading and diffusion factor are required at the meanline and hub. 


\section{Results and Discussion}

\subsection{Baseline Micro Turbojet Simulation Results and Discussion}

The simulation uses the boundary conditions input data such as; rotational speed, compressor inlet mass flow rate, inlet pressure and temperature, the combustor outlet temperature and the turbine efficiency (as specified in the previous section) and applies the matrix iteration component matching method to compute the engine performance parameters. The system fuel flow rate and the turbine mass flow rate is then determined based on the combustor outlet temperature, fuel heating value and the compressor mass flow rate. The simulation of the baseline GasTurb turbojet model is performed at altitude engine test facility with ISA ambient conditions at $0 \mathrm{~m}$ altitude, the results may be seen below in Figure 11

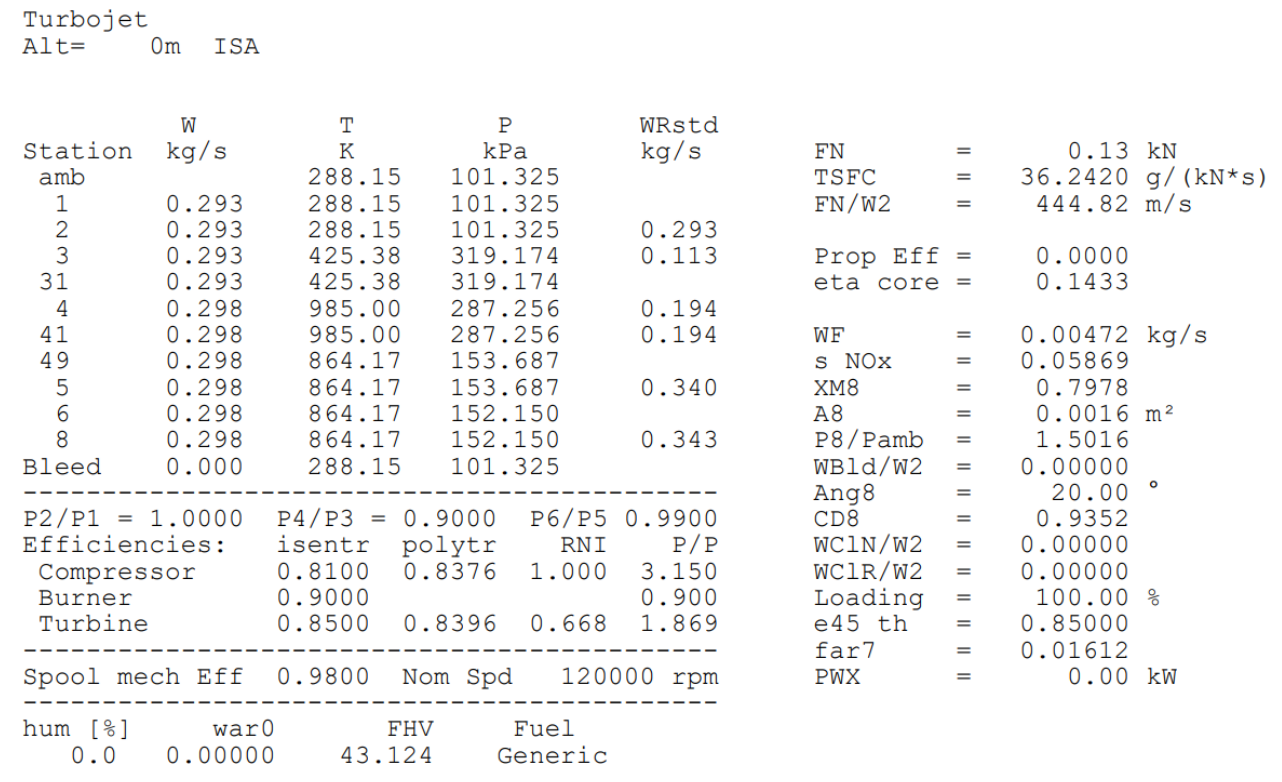

Figure 11. GasTurb simulation results for baseline turbojet, test facility

From the results, a good agreement is achieved between the simulated results in GasTurb and experimental data available from [6] for a spool speed of 120,000 RPM. A thrust of $130 \mathrm{~N}$ is simulated in comparison to the recorded experimental value of $136.6 \mathrm{~N}$. And simulated fuel mass flow of $0.00472 \mathrm{~kg} / \mathrm{s}$ in comparison to $0.0063 \mathrm{~kg}$. Variations in the values may be attributed to the ambient conditions at the test facility during the experimental testing and additional frictional losses in the bearing and lubrication. Figure 12 below shows the thermodynamic states of the cycle and is used to further analysis the validity of the simulation. The clear additional of $\mathrm{m}_{\mathrm{f}}$ to $\mathrm{ma}$ may be seen at station 3 as part of the combustion process and then remains constant after exiting the burner. The variations in total temperature and pressure align with expectations of thermodynamic states through compression, combustion and expansion, whilst the static pressure changes throughout the cycle. 


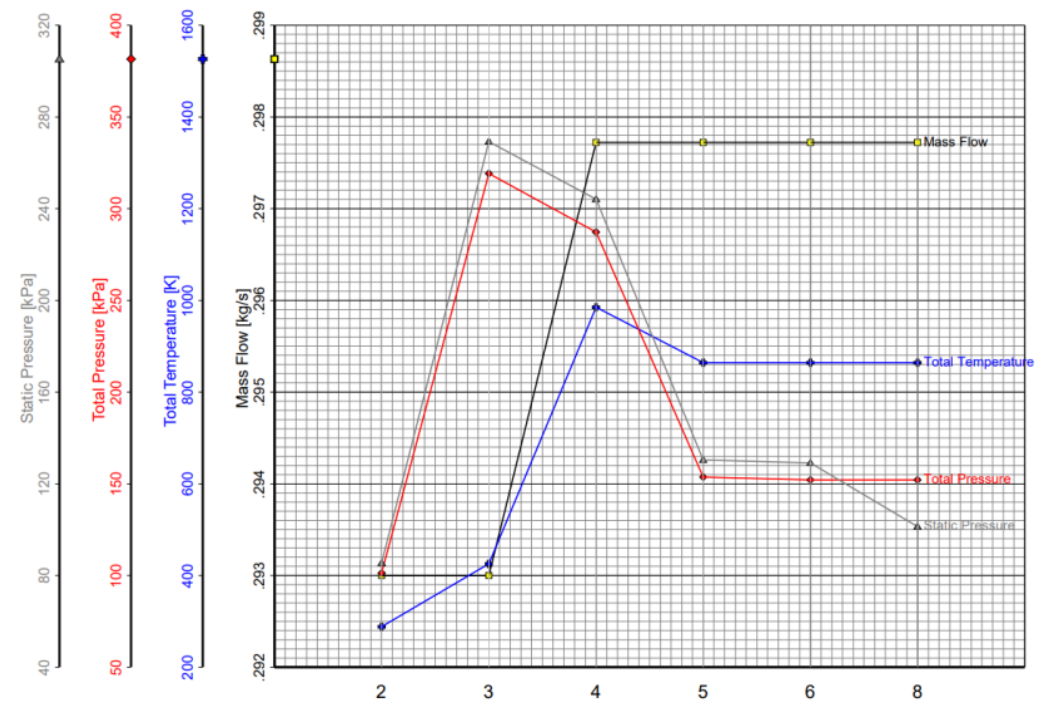

Figure 12. Station properties for baseline turbojet simulation at $0.13 \mathrm{kN}$

\subsection{Micro Turbofan Conversion Results And Discussion}

GasTurb engine performance results for converted turbofan cycle analysis are shown in Figure 13 to Figure 14. Shown below are the final arrived at results after significant iteration for the design point of the converted turbofan. Thermodynamic analysis of the engine cycle yields that the engine achieves a thrust value of $180 \mathrm{~N}$ with a TSFC of $36.4814 \mathrm{~g} / \mathrm{kNs}$. This performance is at an engine core nominal design speed of $120 \mathrm{kRPM}$, fan speed $30 \mathrm{kRPM}$ with total mass flow rate of $2.02 \mathrm{~kg} / \mathrm{s}$ at a bypass ratio of 5.54. For the fan speed of 30,432 RPM the finalized values for the LPC inner pressure rise, 1.08 at an efficiency of 0.815 and LPC outer, 1.075 at an efficiency of 0.81 .

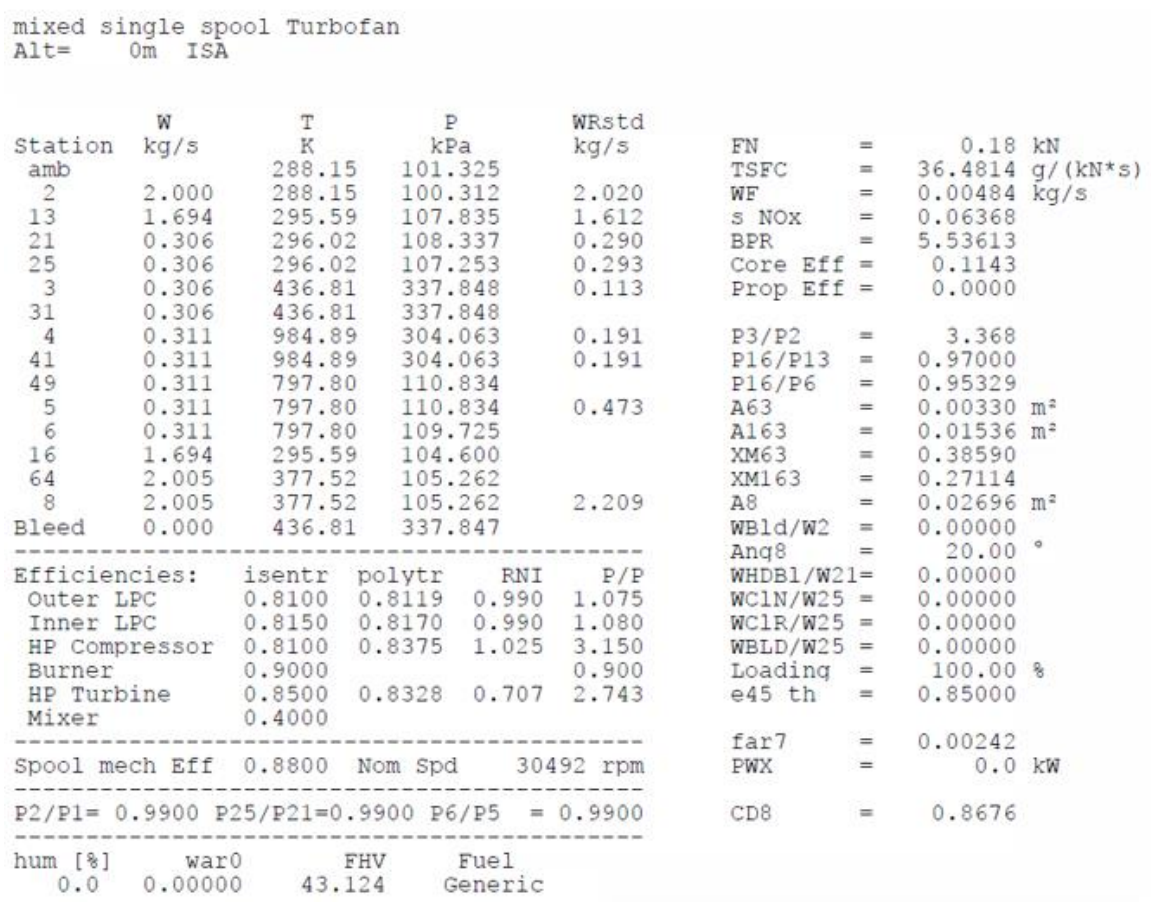

Figure 13. GasTurb simulation results for fan speed 30,492 RPM 
Figure 14 displays results for investigation into varying gear ratios for the low-pressure compressor of converted turbofan in comparison to original baseline micro turbojet. The results highlight the potential advantage of variable gear ratio coupled LPC to the original micro turbojet, flexibility to adjust LPC performance for operational flight requirements. The additional input and output parameter for the varying spool speed simulations may be seen in appendix A, the procedure followed is the same as described throughout this paper. As expected, fan operation at close to maximum spool speed with increased efficiency, higher mass and increased total pressure rise yields significantly higher thrust values $180 \mathrm{~N}>130 \mathrm{~N}, 38.46 \%$ increase. Conversely, for efficiency fan speed operation at 13,068 RPM yields a significant increase in TSFC of $60 \mathrm{~g} /\left(\mathrm{kN}^{*} \mathrm{~s}\right)>36 \mathrm{~g} /\left(\mathrm{kN}^{*} \mathrm{~s}\right), 65.8 \%$ increase.

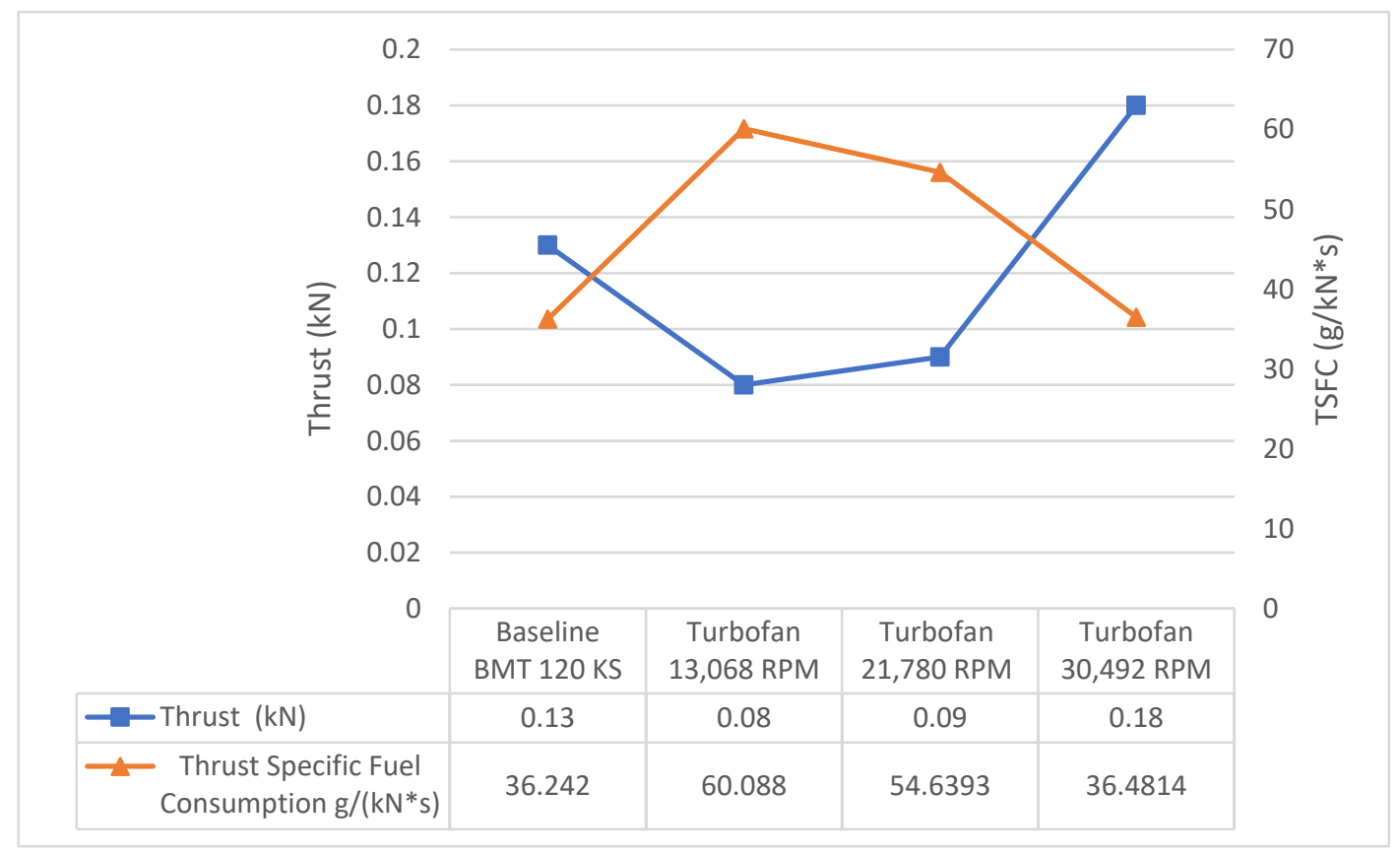

Figure 14. Comparison of baseline turbojet simulated results to converted turbofan at variable gear ratios

\subsection{Low Pressure Compressor Preliminary Aerodynamic Design}

\subsubsection{One Dimensional Meanline Calculation}

The LPC design point for varying speeds was identified through iteration of performance values taken from a scaled fan map and simulated with GasTurb engine performance software. The first step of the design procedure is to make the appropriate assumptions and calculations for LPC efficiency, tip speed, axial velocity and related parameters. First, a constraint of fan tip relative Mach number $\leq 1$ (LPC tip speed $=330 \mathrm{~m} / \mathrm{s}$ ) is imposed and therefore avoiding associated wave drag from the supersonic flow. Inlet Mach number is fixed at $0.5(\approx 160 \mathrm{~m} / \mathrm{s})$ for the design point of cruise conditions. The design parameters already identified from engine simulation are as follows:

$$
\begin{gathered}
\text { Ambient conditions: } P_{0}=1.01325 \text { bar }, T_{0}=288.15 \mathrm{~K} \\
\text { Mass Flow Rate of Air: } \dot{m}_{a}=2.02 \frac{\mathrm{kg}}{\mathrm{s}} \\
\text { Compressor Ratio: } \frac{P_{02}}{P_{01}}=1.08
\end{gathered}
$$




$$
\text { Nominal Spool Speed: } N=30,492 \text { RPM }=508.2 \frac{\mathrm{rev}}{\mathrm{sec}}
$$

$$
\text { Efficiency: } \eta=0.815
$$

Next the overall annulus dimensions, inlet and outlet of compressor (hub-to-tip ratio $-\mathrm{rh}=$ hub radius, $\mathrm{r}_{\mathrm{t}}=$ tip radius) are sized (see Figure 16).

$$
\begin{gathered}
\text { Tip Speed: } U_{t}=330 \frac{\mathrm{m}}{\mathrm{s}} \\
\text { Axial Velocity: } C_{a}=160 \frac{\mathrm{m}}{\mathrm{s}},
\end{gathered}
$$

From the lessons learned in [2] no IGV is employed as it is assumed in the design of this LPC similar drops in efficiency can be expected due blading and increased shock losses. Therefore, therefore no whirl velocity component is assumed in the calculation. From isentropic flow equations: $(\mathrm{Cp}=1.005$ $\mathrm{KJ} / \mathrm{kg}, \mathrm{R}=287 \mathrm{~J} / \mathrm{kg}$ )

$$
\begin{gathered}
T_{1}=288.15-\frac{170^{2}}{2 \times 1005}=275.4 \mathrm{~K} \\
P_{1}=1.01325\left(\frac{275.4}{288.15}\right)^{3.5}=0.865 \mathrm{bar} \\
\rho_{1}=\frac{0.865 \mathrm{e} 5}{287 \times 275.4}=1.09 \frac{\mathrm{kg}}{\mathrm{m}^{3}}
\end{gathered}
$$

From the continuity equation:

$$
\begin{gathered}
m=\rho_{1} A C_{a 1}=\rho_{1} \pi r_{t}^{2}\left[1-\left(\frac{r_{h}}{r_{t}}\right)^{2}\right] C_{a 1} \\
r_{t}^{2}=\frac{m}{\rho_{1} \pi C_{a 1}\left[1-\left(\frac{r_{h}}{r_{t}}\right)^{2}\right]}=\frac{0.00367}{\left[1-\left(\frac{r_{h}}{r_{t}}\right)^{2}\right]}
\end{gathered}
$$

Tip speed, tip radius and nominal spool speed are related by:

$$
U_{t}=2 \pi N r_{t}
$$

Thus, with the use of a simple spreadsheet and the above equations the tip radius and spool speed can be evaluated over a range of different hub to tip ratios. The purpose of the evaluation is to iterate the variables of hub-tip ratio and blade tip speed to reach a target nominal speed as close to 30,492 RPM as possible, thus keeping the design parameters close to results from the engine simulation.

Table 5. Variations of hub-tip ratio with spool speed

\begin{tabular}{|c|c|c|c|c|}
\hline $\mathbf{r}_{\mathbf{h}} / \mathbf{r}_{\mathbf{t}}$ & $\mathbf{r}_{\mathbf{t}}(\mathbf{m})$ & $\mathbf{N}\left(\frac{\mathbf{r e v}}{\mathbf{s e c}}\right)$ & $\mathbf{N}(\mathbf{R P M})$ & $\begin{array}{c}\text { Annulus } \\
\text { Diameter }(\mathbf{m})\end{array}$ \\
\hline 0.40 & 0.0661 & 542 & 32,495 & 132.24 \\
\hline 0.41 & 0.0664 & 539 & 32,338 & 132.88 \\
\hline 0.42 & 0.0668 & 536 & 32,176 & 133.55 \\
\hline 0.43 & 0.0671 & 533 & 32,010 & 134.25 \\
\hline 0.44 & 0.0675 & 531 & 31,839 & 134.97 \\
\hline 0.45 & 0.0679 & 528 & 31,662 & 135.72 \\
\hline 0.46 & 0.0682 & 525 & 31,481 & 136.50 \\
\hline 0.47 & 0.0687 & 522 & 31,295 & 137.31 \\
\hline 0.48 & 0.0691 & 518 & 31,104 & 138.16 \\
\hline
\end{tabular}




\begin{tabular}{|l|l|l|l|l|}
\hline 0.49 & 0.0695 & 515 & 30,907 & 139.04 \\
\hline 0.50 & 0.0700 & 512 & 30,705 & 139.95 \\
\hline 0.51 & 0.0705 & 508 & 30,498 & 140.90 \\
\hline 0.52 & 0.0709 & 505 & 30,285 & 141.89 \\
\hline 0.53 & 0.0715 & 501 & 30,066 & 142.93 \\
\hline 0.54 & 0.0720 & 497 & 29,841 & 144.00 \\
\hline 0.55 & 0.0726 & 494 & 29,611 & 145.12 \\
\hline 0.56 & 0.0731 & 490 & 29,374 & 146.29 \\
\hline 0.57 & 0.0738 & 486 & 29,132 & 147.51 \\
\hline 0.58 & 0.0744 & 481 & 28,882 & 148.78 \\
\hline 0.59 & 0.0751 & 477 & 28,627 & 150.11 \\
\hline 0.60 & 0.0758 & 473 & 28,364 & 151.50 \\
\hline
\end{tabular}

Table 5 presents the results of the study. The initial selection of tip speed at $330 \mathrm{~m} / \mathrm{s}$ is chosen as an upper limit, to reach a satisfactory solution the tip speed is reduced to $225 \mathrm{~m} / \mathrm{s}$. At a hub-tip ratio of 0.51 , the speed is equal to 30,498 RPM, which is sufficient to match the required parameters. The hub to tip ratio of 0.51 is selected as an arbitrary starting point and the study is conducted from $0.4-$ 0.6. A high hub-tip ratio results in an increased annulus diameter and increases the overall weight of the system, it may be seen that the blades would be approximately $70 \mathrm{~mm}$ for annulus dimension of $150 \mathrm{~mm}$. Conversely a practical limit of the blade size must be realised and an overly small hub-tip ratio results in blade around $66 \mathrm{~mm}$. The hub-tip ratio will be later studied and adjusted in more detail from numerical analysis. The relative Mach number at the rotor tip is calculated to validate results. From the velocity triangle:

$$
\begin{gathered}
V_{1 t}=\sqrt{U_{t}^{2}+C_{a 1}^{2}}=\sqrt{225^{2}+160^{2}}=276.1 \frac{\mathrm{m}}{\mathrm{s}} \\
a=\sqrt{\gamma R T_{1}}=332.7 \frac{\mathrm{m}}{\mathrm{s}} \\
M_{t}=\frac{V_{1 t}}{a}=0.83
\end{gathered}
$$

Therefore, an acceptable subsonic relative Mach number at the rotor tip of 0.83 is calculated. The LPC inlet parameters are validated using GasTurb software. For the chosen design point along the 30,492 RPM speed line the LPC design parameters are input. Iteration variables such as; LPC inlet radius ratio, design bypass ratio, LPC outer pressure ratio are set and target design spool speed is set as the studied fan map speed line. Upon simulation, GasTurb iterates between variables and converges on an acceptable solution with independent variables, LPC Inlet Radius Ratio and Design Spool Speed, that the criteria for fan preliminary design. Figure 15 shows the results for LPC preliminary design reached after numerous iterations. A design spool speed of 30,494 RPM is achieved which matches the scaled performance curve by an acceptable degree for this stage. At this spool speed a minimum 4:1 reduction gearbox is required to separate the fan from core spool speed of 120,000 RPM. It may also be seen that the LPC diameter is calculated at $140 \mathrm{~mm}$, which considering the $110 \mathrm{~mm}$ inlet of the BMT $120 \mathrm{KS}$ is an acceptable solution for a low bypass solution. 


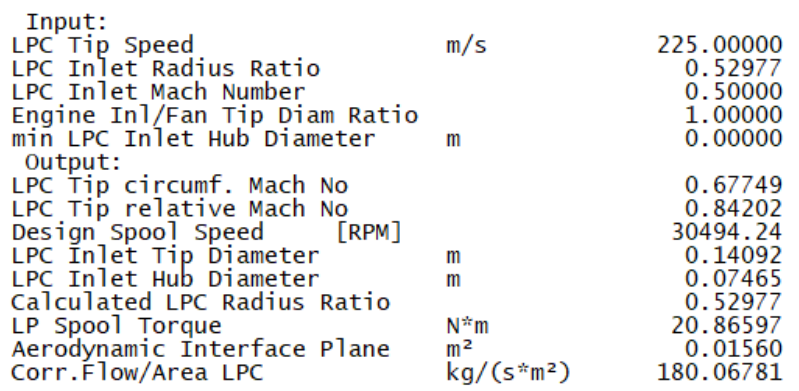

Figure 15. GasTurb model LPC design parameters

The aerodynamic inlet operating conditions determined previous are used as the initial design parameters in the mean line analysis, as seen below in Table 6. Total pressure rises through rotor after any downstream pressure losses, neglecting swirl component. Downstream mixing losses specifies the proportion of axial dynamic pressure at rotor exit that is assumed lost due to aerodynamic mixing process which, left as the default value of $25 \%$ which offers a robust solution. Hub velocity deficit factor is used to adjust the meanline calculation to take into account the influence of the boundary layer at the hub.

Table 6. Aerodynamic input for meanline calculation

\begin{tabular}{|c|c|c|}
\hline \multicolumn{3}{|c|}{ Aerodynamic Inputs } \\
\hline Property & Value & Unit \\
\hline Rotational speed & 30492 & $\mathrm{rev} \mathrm{min}^{\wedge}-1$ \\
\hline Mass flow rate & 2.02 & $\mathrm{~kg} \mathrm{~s}^{\wedge}-1$ \\
\hline Inlet Stagnation Pressure & 101325 & $\mathrm{~Pa}$ \\
\hline Inlet Stagnation Temperature & 288 & $\mathrm{~K}$ \\
\hline Total Pressure Rise & 8100 & $\mathrm{~Pa}$ \\
\hline Efficiency Estimate & 0.81 & \\
\hline Downstream Mixing Losses & 0.25 & \\
\hline Hub Velocity Deficit Factor & 1 & \\
\hline Hub Loading Parameter & 1 & \\
\hline
\end{tabular}

With the aerodynamic inputs defined, for one dimensional meanline calculations the remaining parameters effecting results are the outer diameter, hub/tip ratio inlet and hub/tip outlet (see Figure 16). Initial LPC annulus/rotor geometry are calculated from GasTurb engine model simulation are used as the start point for flow through analysis of geometry inputs. The inlet tip diameter calculated at $0.14092 \mathrm{~m}$ provides a first good estimate for the annulus outer dimensions. At a hub-tip ratio of 0.53 , the resulting blade height estimate is $66.27 \mathrm{~mm}$, thus the tip clearance is $4.19 \mathrm{~mm}$ or s/h=0.05, for this stage is sufficient. The clearance has a strong effect on the efficiency, however is not modelled in the meanline calculation and is for consideration at later design phase. 

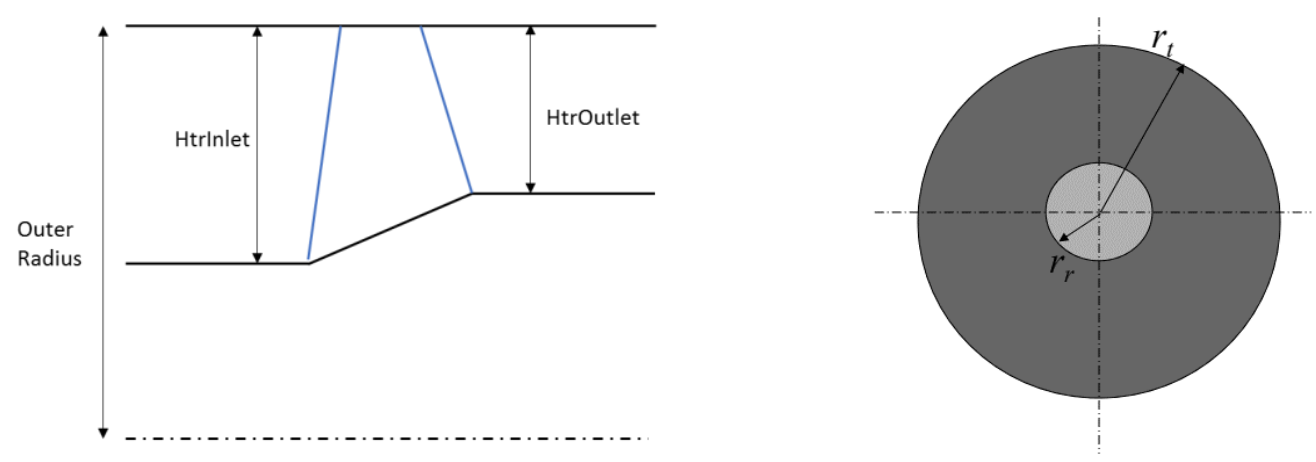

Figure 16. Diagram explaining geometry input parameters

Evaluation of initial meanline calculation results for an annulus outer diameter of $0.141 \mathrm{~m}$ and hub-tip ratio 0.53 produces unsatisfactory results. It is found that the hub is overly loaded with the minimum stage loading calculated at 0.95 for hub-tip ratio equal to 0.53 , in addition to the flow coefficient exceeding the $<0.8$ criterion for both meanline and hub. The study is expanded to allow for slight modification of the annulus dimensions, considerations include; an outer diameter that is too large for the duty will suffer from increase swirl and associated pressure losses. Equally, too small of diameter will lead to higher loadings and reduced DeHaller number.

To achieve acceptable solutions for the meanline calculation, the annulus outer diameter is required to be increased. From further sizing of the LPC inlet and with reference to Table 5 it is calculated that the maximum obtainable annulus size, limited by relative tip Mach number, whilst maintaining initial input aerodynamic parameters (mass flow/spool speed/pressure ratio) is $0.17 \mathrm{~m}$, this is validated in GasTurb and results may be seen in the below figure.

$\begin{array}{llr}\text { Input: } & \mathrm{m} / \mathrm{s} & \\ \text { LPC Tip Speed } & & 270.40152 \\ \text { LPC Inlet Radius Ratio } & 0.50000 \\ \text { LPC Inlet Mach Number } & & 0.50000 \\ \text { Engine InT/Fan Tip Diam Ratio } & & 1.00000 \\ \text { min LPC Inlet Hub Diameter } & \mathrm{m} & 0.12000 \\ \text { Output: } & & \\ \text { LPC Tip circumf. Mach No } & & 0.81419 \\ \text { LPC Tip relative Mach No } & & 0.95546 \\ \text { Design Spool Speed } & & 30492.00 \\ \text { LPC Inlet Tip Diameter } & \mathrm{m} & 0.16937 \\ \text { LPC In1et Hub Diameter } & \mathrm{m} & 0.12000 \\ \text { Calculated LPC Radius Ratio } & & 0.70853 \\ \text { LP Spool Torque } & \mathrm{N}^{* m} & 20.86750 \\ \text { Aerodynamic Interface Plane } & \mathrm{m}^{2} & 0.02253 \\ \text { Corr.Flow/Area LPC } & \mathrm{kg} /\left(\mathrm{s}^{*} \mathrm{~m}^{2}\right) & 180.06781\end{array}$

Figure 17. LPC design in GasTurb software for annulus diameter $0.17 \mathrm{~m}$

Different values for the annulus diameter up to $0.17 \mathrm{~m}$ are analyzed. Figure 18 through to Figure 20 shows the graphical results of the meanline calculation for the study of annulus outer diameter. The design point is associated with the hub-tip inlet which is varied at +0.01 from $0.4-0.6$ for the study. 


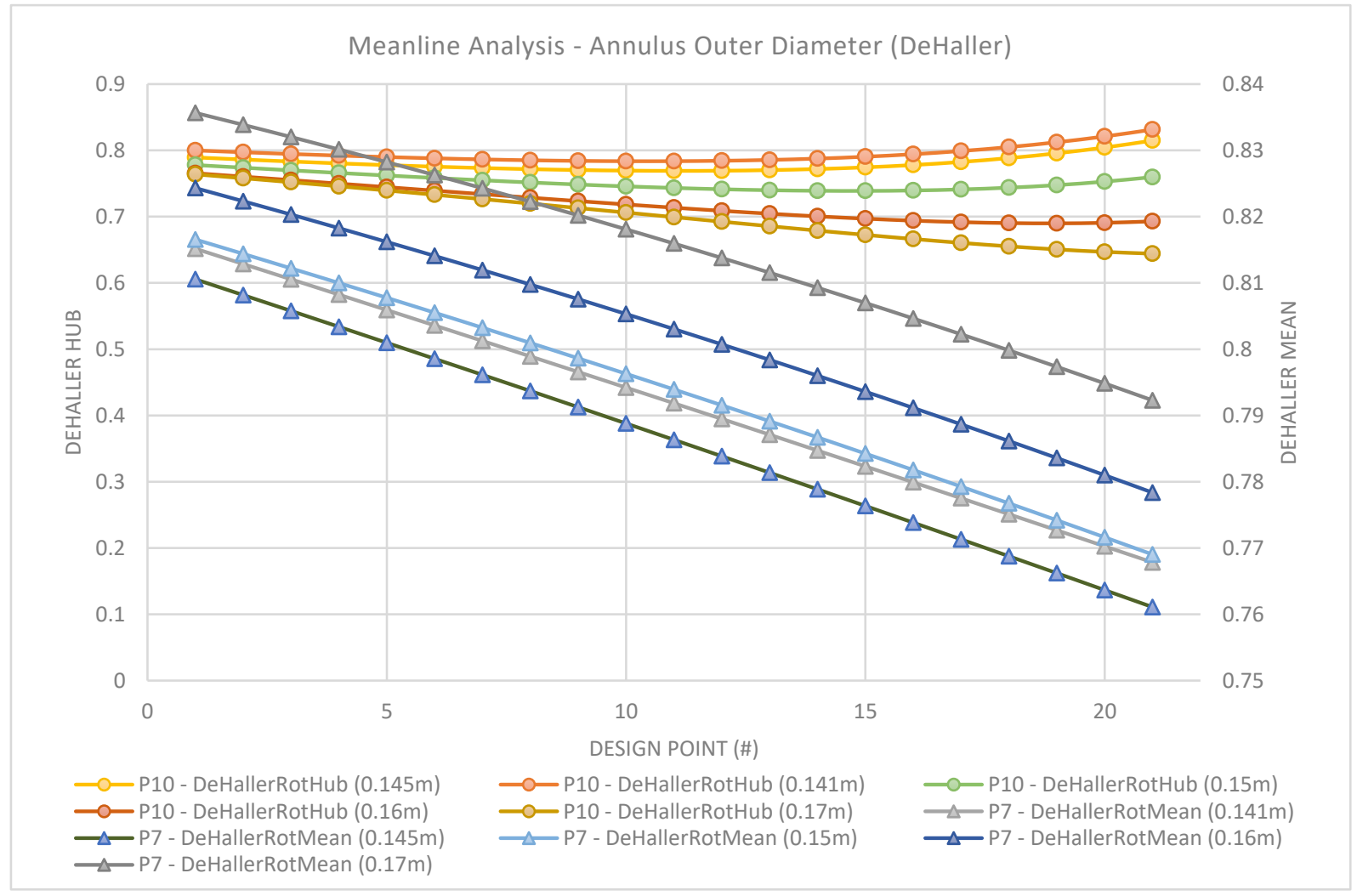

Figure 18. Meanline analysis for outer diameter (DeHaller number)

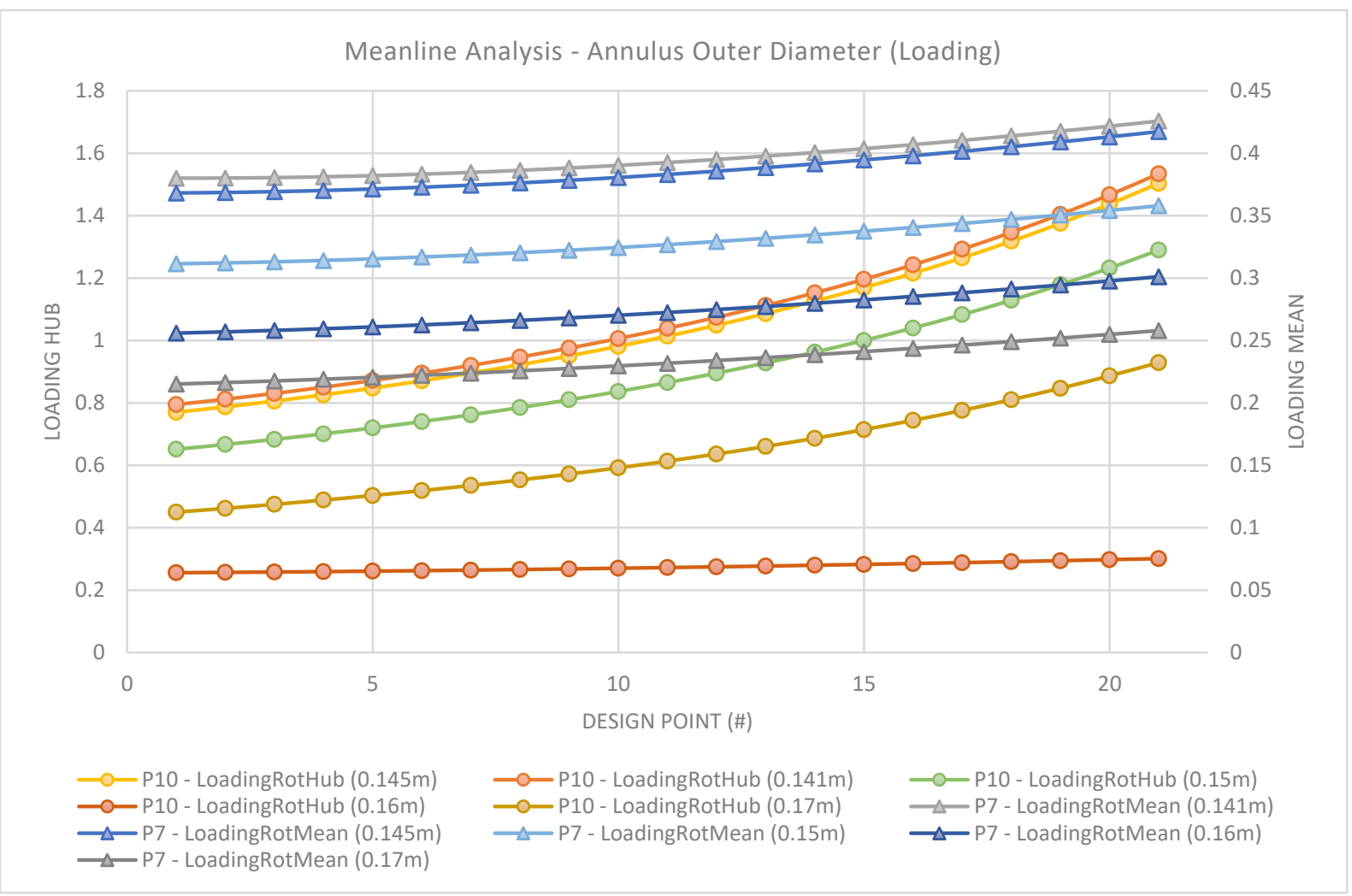

Figure 19. Meanline analysis for annulus outer diameter (loading) 


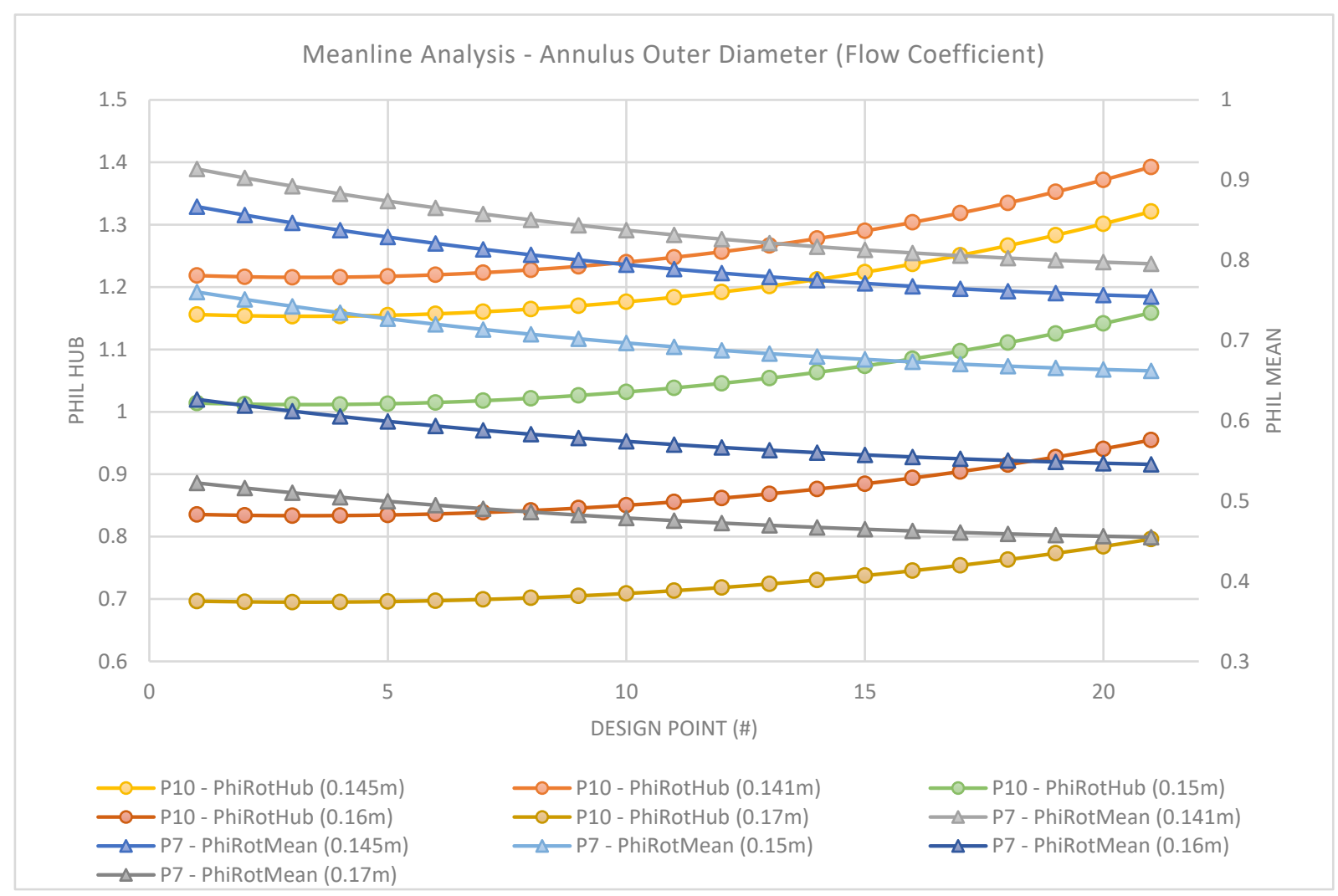

Figure 20. Meanline Analysis - Annulus outer diameter (flow coefficient)

Studying the three above figures it may be seen that the meanline and hub for all annulus diameter satisfies the criteria of DeHaller $>0.72$. And a smaller annulus diameter produces more favorable results in terms of meanline DeHaller, especially approaching higher hub-tip ratios of more than 0.55 (DP 15). However, as a consequence, the hub becomes highly loaded, which significantly impacts the efficiency. Moreover, from the evaluation of the loading coefficient $(\psi)$ it is apparent that for all annulus dimensions but $0.17 \mathrm{~m}$ a suitable design would not be achievable as hub $\psi$ exceeds 1 . Finally, the flow coefficient which is given by the axial velocity over the rotational speed of the rotor and thus dependent only on the inlet hub to tip ratio. An acceptable solution for the flow coefficient should be below 0.8 , which again leaves 0.17 outer diameter as the more suitable value.

With the outer annulus diameter determined, the hub/tip ratio input and output parameters are then varied during an iteration study to determine the optimum values for the 1D meanline analysis. It is advantageous to increase the outer hub/tip over the inlet in order to accelerate the axial flow increasing overall pressure rise of the stage and assist in the prevention of stall. For the first set of data, the hub/tip inlet and outlet values are constant (i.e. HtrInlet $=0.53$ and HtrOutlet $=0.53$ ). After the baseline evaluation is complete the values are iterated at +0.01 intervals from 0.4-0.6 to estimate the performance for given aerodynamic and geometric input parameters, A table displaying the meanline analysis iteration process may be seen below.

Table 7. Iteration procedure for meanline analysis of annulus outer diameter $0.17 \mathrm{~m}$

\begin{tabular}{|c|c|c|c|c|c|c|c|}
\hline \multicolumn{2}{|c|}{} & \multicolumn{6}{|c|}{ Hub-Tip Ratio Outlet Iteration } \\
\hline $\begin{array}{c}\text { Design } \\
\text { Point }\end{array}$ & $\begin{array}{c}\text { Hub-Tip Ratio } \\
\text { Inlet }\end{array}$ & $\mathbf{1}$ & $\mathbf{2}$ & $\mathbf{3}$ & $\mathbf{4}$ & $\mathbf{5}$ & $\mathbf{6}$ \\
\hline 0 & 0.6 & 0.6 & 0.61 & 0.62 & 0.63 & 0.64 & 0.65 \\
\hline 1 & 0.59 & 0.59 & 0.6 & 0.61 & 0.62 & 0.63 & 0.64 \\
\hline 2 & 0.58 & 0.58 & 0.59 & 0.6 & 0.61 & 0.62 & 0.63 \\
\hline
\end{tabular}




\begin{tabular}{|c|c|c|c|c|c|c|c|}
\hline 3 & 0.57 & 0.57 & 0.58 & 0.59 & 0.6 & 0.61 & 0.62 \\
\hline 4 & 0.56 & 0.56 & 0.57 & 0.58 & 0.59 & 0.6 & 0.61 \\
\hline 5 & 0.55 & 0.55 & 0.56 & 0.57 & 0.58 & 0.59 & 0.6 \\
\hline 6 & 0.54 & 0.54 & 0.55 & 0.56 & 0.57 & 0.58 & 0.59 \\
\hline 7 & 0.53 & 0.53 & 0.54 & 0.55 & 0.56 & 0.57 & 0.58 \\
\hline 8 & 0.52 & 0.52 & 0.53 & 0.54 & 0.55 & 0.56 & 0.57 \\
\hline 9 & 0.51 & 0.51 & 0.52 & 0.53 & 0.54 & 0.55 & 0.56 \\
\hline 10 & 0.5 & 0.5 & 0.51 & 0.52 & 0.53 & 0.54 & 0.55 \\
\hline 11 & 0.49 & 0.49 & 0.5 & 0.51 & 0.52 & 0.53 & 0.54 \\
\hline 12 & 0.48 & 0.48 & 0.49 & 0.5 & 0.51 & 0.52 & 0.53 \\
\hline 13 & 0.47 & 0.47 & 0.48 & 0.49 & 0.5 & 0.51 & 0.52 \\
\hline 14 & 0.46 & 0.46 & 0.47 & 0.48 & 0.49 & 0.5 & 0.51 \\
\hline 15 & 0.45 & 0.45 & 0.46 & 0.47 & 0.48 & 0.49 & 0.5 \\
\hline 16 & 0.44 & 0.44 & 0.45 & 0.46 & 0.47 & 0.48 & 0.49 \\
\hline 17 & 0.43 & 0.43 & 0.44 & 0.45 & 0.46 & 0.47 & 0.48 \\
\hline 18 & 0.42 & 0.42 & 0.43 & 0.44 & 0.45 & 0.46 & 0.47 \\
\hline 19 & 0.41 & 0.41 & 0.42 & 0.43 & 0.44 & 0.45 & 0.46 \\
\hline 20 & 0.4 & 0.4 & 0.41 & 0.42 & 0.43 & 0.44 & 0.45 \\
\hline
\end{tabular}

Figure 21 through to Figure 23 presents the results of the study for evaluating hub to tip ratio for the rotor at the annulus outer diameter of $0.17 \mathrm{~m}$. In this study, the objective is to find the optimum annulus geometry and size before further study and optimization is conducted with throughflow calculation.

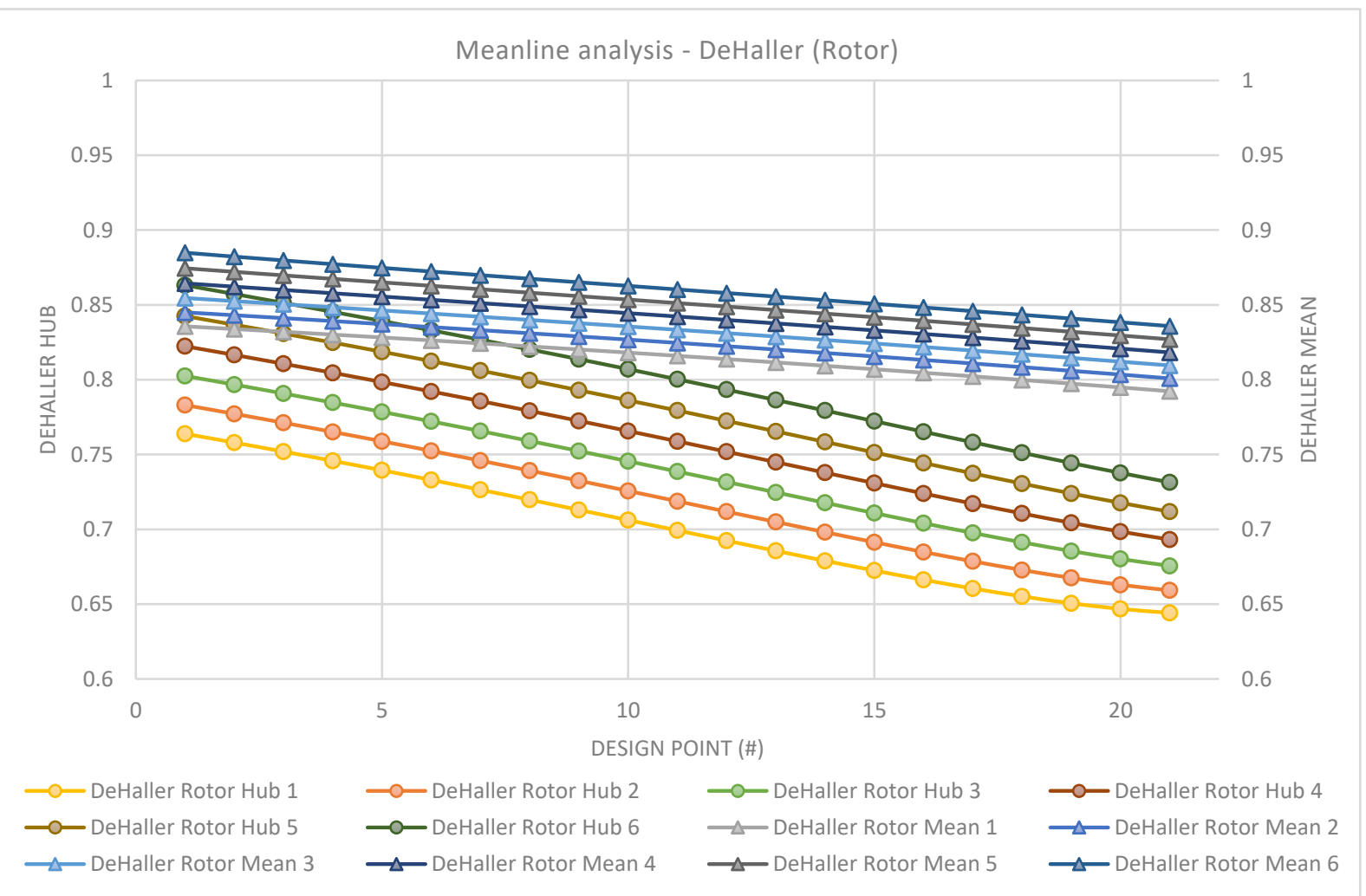

Figure 21. Meanline analysis - DeHaller number (Rotor) 


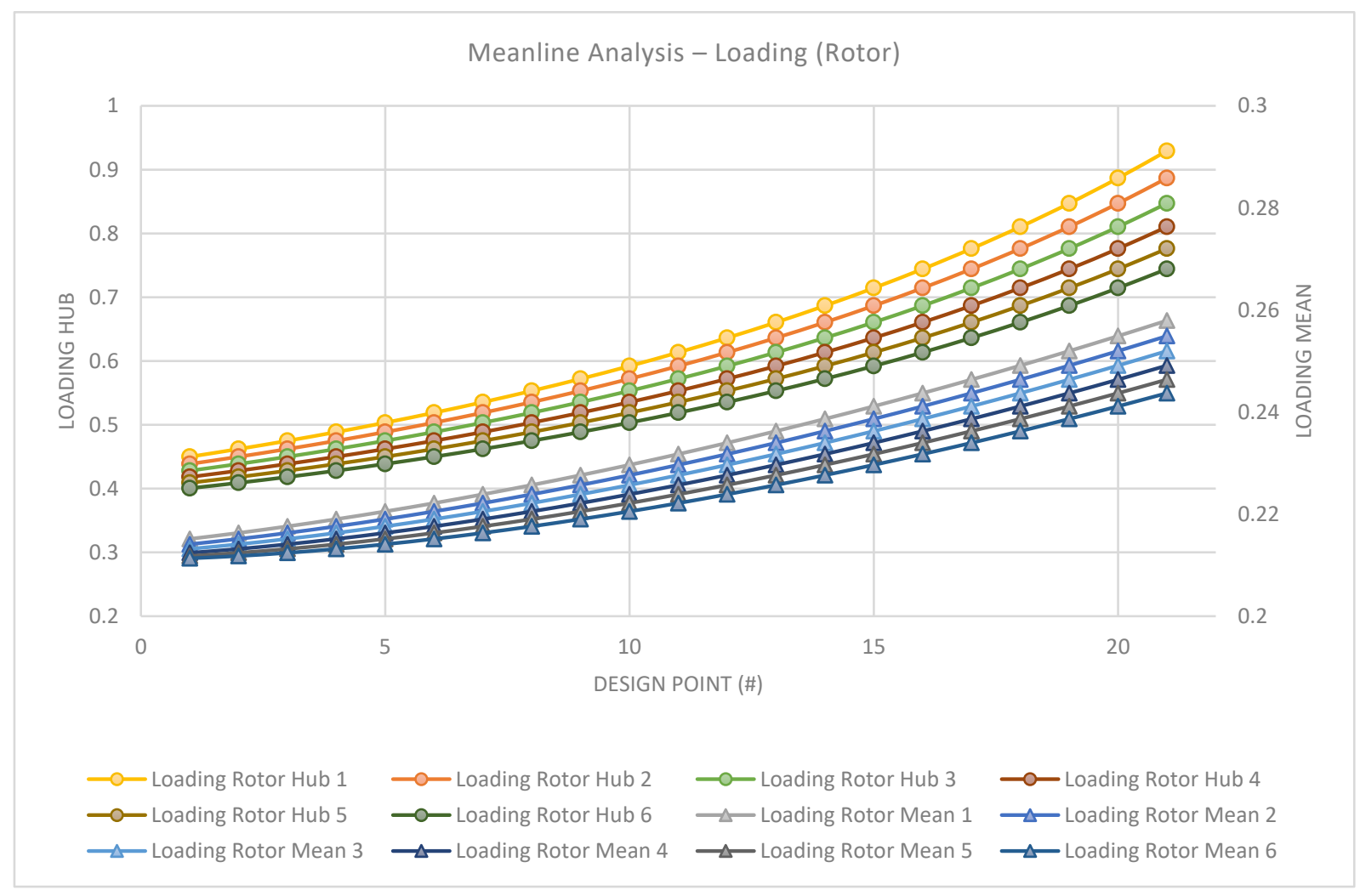

Figure 22. Meanline Analysis - Loading (Rotor)

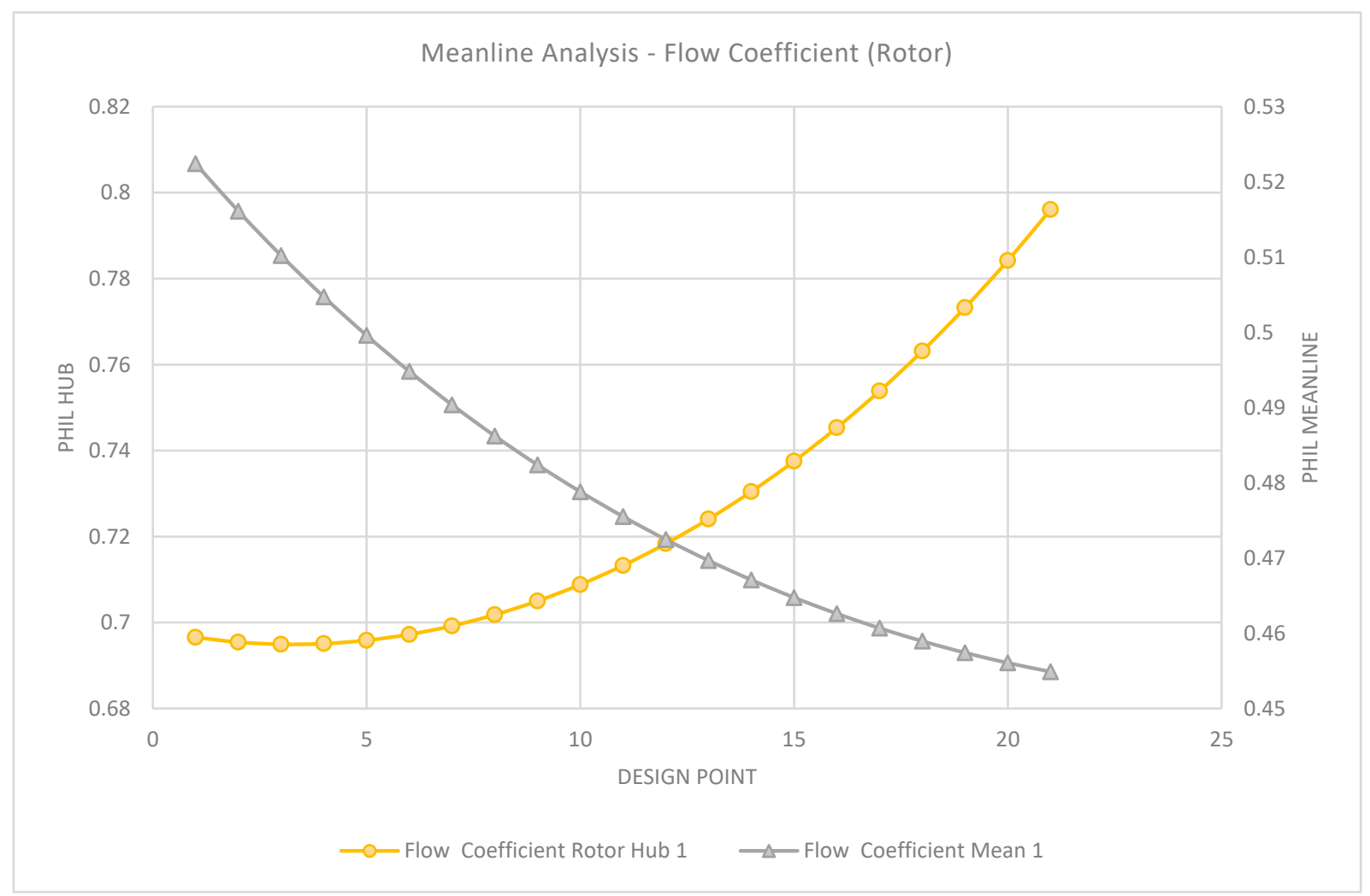

Figure 23. Meanline Analysis - Flow Coefficient

Figure 21 shows the meanline flow analysis DeHaller number results graphically. The graph is used in conjunction with numerical data to determine geometry to produce preferable results in 
terms of DeHaller number $\left(\mathrm{V}_{2} / \mathrm{V}_{1}>0.72\right)$. It's clearly observed that increasing hub-tip ratio at the outlet over the inlet increases axial velocity, for example, design point 6 (HtrInlet 0.54, HtrOutlet 0.54) with hub DeHaller 0.72 and meanline 0.82 compared to the last iteration (HtrInlet 0.54, HtrOutlet 0.59) with equivalent hub DeHaller 0.82 and meanline 0.86 . Iteration 1 to 3 for design points 1 to 10 proved geometry with preferable hub DeHaller, meanline DeHaller remains high for all evaluated geometry indicating light aerodynamic loading i.e. a low rate of diffusion. The loading coefficient for the study is seen in Figure 22. As stated in the background section, from studies it is found peak efficiency of the compressors peak around loading coefficient $0.35-0.42$. From evaluation of the loading coefficient design points 1-10 present geometry with a slightly increased aerodynamic loading for peak efficiency with low loaded meanline. Increasing the hub-tip ratio above 0.5 results in an excessively loaded hub. Figure 23 shows the flow coefficient for the meanline calculation, where all design points meet the criteria of $<0.8$. Hub flow coefficient is preferable in the region of design points 1-12.

\subsubsection{Meanline Calculation Summary}

The preliminary meanline calculation of the LPC design is conducted in this section where an iterative study is conducted for the independent variables of the hub to tip inlet and outlet. From the results, it is determined that iteration 1 and 2 for design points $0-10$ produce sets of geometry that are satisfactory and meet the performance criteria to be carried forward to $2 \mathrm{D}$ throughflow analysis. Table 8 and Table 9 show the performance of two better performing geometry configuration to be analyzed further. At this stage, estimates of rotor adiabatic efficiencies (taken as the efficiency estimate in the meanline calculation) are around $85 \%$. All performance results yield a satisfactory value, i.e. flow coefficient is $<0.8$, DeHaller number $>0.72$, and loading which is case dependent on the DeHaller $<0.5$ for higher efficiencies. The initial results show that the rotor is more highly loaded at the hub and more lightly loaded at the tip. The results are influenced by the hub loading parameter from the aerodynamic inputs and may be adjusted to redistribute the workload and thus reduce the loading at the hub of the rotor whilst maintaining the overall pressure rise. However, for the micro gas turbine machinery, it is expected that the hub is more highly loaded due to the increased max flux that concentrates around the hub. In addition, the relative low hub/tip ratios commonly lead to higher hub loadings, at the fixed outer diameter of $0.17 \mathrm{~m}$, the range of selected hub/tip ratios yield a vane chord height of just $\approx 5 \mathrm{~cm}$.

Table 8. Results from 1D meanline analysis for design point 4, iteration 1

\begin{tabular}{|c|c|}
\hline \multicolumn{2}{|c|}{ Rotor (Meanline) } \\
\hline Flow Coefficient & 0.5 \\
\hline Loading & 0.221 \\
\hline DeHaller & 0.828 \\
\hline Gas Exit Angle & 23.82 \\
\hline \multicolumn{2}{|c|}{ Rotor (Hub) } \\
\hline Flow Coefficient & 0.696 \\
\hline Loading & 0.503 \\
\hline DeHaller & 0.739 \\
\hline Gas Exit Angle & 31.58 \\
\hline
\end{tabular}

Table 9. Results from 1D meanline analysis for design point 4 , iteration 2

\begin{tabular}{|c|c|}
\hline \multicolumn{2}{|c|}{ Rotor (Meanline) } \\
\hline Flow Coefficient & 0.5 \\
\hline Loading & 0.219 \\
\hline DeHaller & 0.837 \\
\hline Gas Exit Angle & 23.46 \\
\hline \multicolumn{2}{|c|}{ Rotor (Hub) } \\
\hline Flow Coefficient & 0.696 \\
\hline
\end{tabular}




\begin{tabular}{|c|c|}
\hline Loading & 0.489 \\
\hline DeHaller & 0.759 \\
\hline Gas Exit Angle & 30.86 \\
\hline
\end{tabular}

\subsubsection{Two-dimensional streamline throughflow analysis}

With satisfactory results from the meanline calculation for a selection of hub tip ratios, the performance study is expanded to include additional aerodynamic dependent input/output parameters. Additional input parameters include the rotor vane aspect ratio, number of vanes and profile trim. The aspect ratio is defined as the blade height/hub chord. From the works of [2] and individual experimentation yielding unacceptable results, it is found for this application common aspect ratios of 3 to 5 cannot be achieved. Thus, the vanes are restricted to aspect ratios around unity, with wide streamwise hub chords ensuring reasonable thickness to maximise the low Reynolds numbers in micro turbomachinery. The profile trim is defined as the chord at the tip chord/hub chord, for the rotor this value is commonly $<1$, reducing the chord with increasing span. In a similar procedure to the meanline calculation, a set of iteration parameters (as seen below) are defined and the variables are iterated for different values. The design points and iterative setup maybe seen in Table 10 (a) and (b) as well as in Figure 31 and Figure 32 in the Appendices. The results of this study may be seen in the following graphs and in the Appendices (Figure 33 and Figure 34).

Table 10. (a) Design Points and (b) iteration procedure for throughflow analysis

(a)

\begin{tabular}{|c|c|c|c|c|c|}
\hline DP 1 & 0.6 & 0.6 & DP 12 & 0.6 & 0.61 \\
\hline DP 2 & 0.59 & 0.59 & DP 13 & 0.59 & 0.6 \\
\hline DP 3 & 0.58 & 0.58 & DP 14 & 0.58 & 0.59 \\
\hline DP 4 & 0.57 & 0.57 & DP 15 & 0.57 & 0.58 \\
\hline DP 5 & 0.56 & 0.56 & DP 16 & 0.56 & 0.57 \\
\hline DP 6 & 0.55 & 0.55 & DP 17 & 0.55 & 0.56 \\
\hline DP 7 & 0.54 & 0.54 & DP 18 & 0.54 & 0.55 \\
\hline DP 8 & 0.53 & 0.53 & DP 19 & 0.53 & 0.54 \\
\hline DP 9 & 0.52 & 0.52 & DP 20 & 0.52 & 0.53 \\
\hline DP 10 & 0.51 & 0.51 & DP 21 & 0.51 & 0.52 \\
\hline DP 11 & 0.5 & 0.5 & DP 22 & 0.5 & 0.51 \\
\hline
\end{tabular}

(b)

\begin{tabular}{|c|c|c|c|c|c|c|}
\hline Iteration & $\begin{array}{c}\text { Aspect } \\
\text { Ratio } \\
\text { Rotor }\end{array}$ & $\begin{array}{c}\text { No. Vanes } \\
\text { Rotor }\end{array}$ & TrimRotor & $\begin{array}{c}\text { Aspect } \\
\text { Ratio } \\
\text { Stator }\end{array}$ & $\begin{array}{c}\text { Trim } \\
\text { Stator }\end{array}$ & $\begin{array}{c}\text { No. Vanes } \\
\text { Stator }\end{array}$ \\
\hline A & 1 & 12 & 1 & 1 & 1 & 14 \\
\hline B & 1 & 14 & 1 & 1 & 1 & 16 \\
\hline C & 1.1 & 12 & 1 & 1.1 & 1 & 14 \\
\hline D & 1.1 & 12 & 0.9 & 1.1 & 1 & 14 \\
\hline E & 1.1 & 10 & 0.9 & 1.1 & 1 & 12 \\
\hline F & 1.2 & 10 & 0.9 & 1.2 & 0.9 & 12 \\
\hline
\end{tabular}




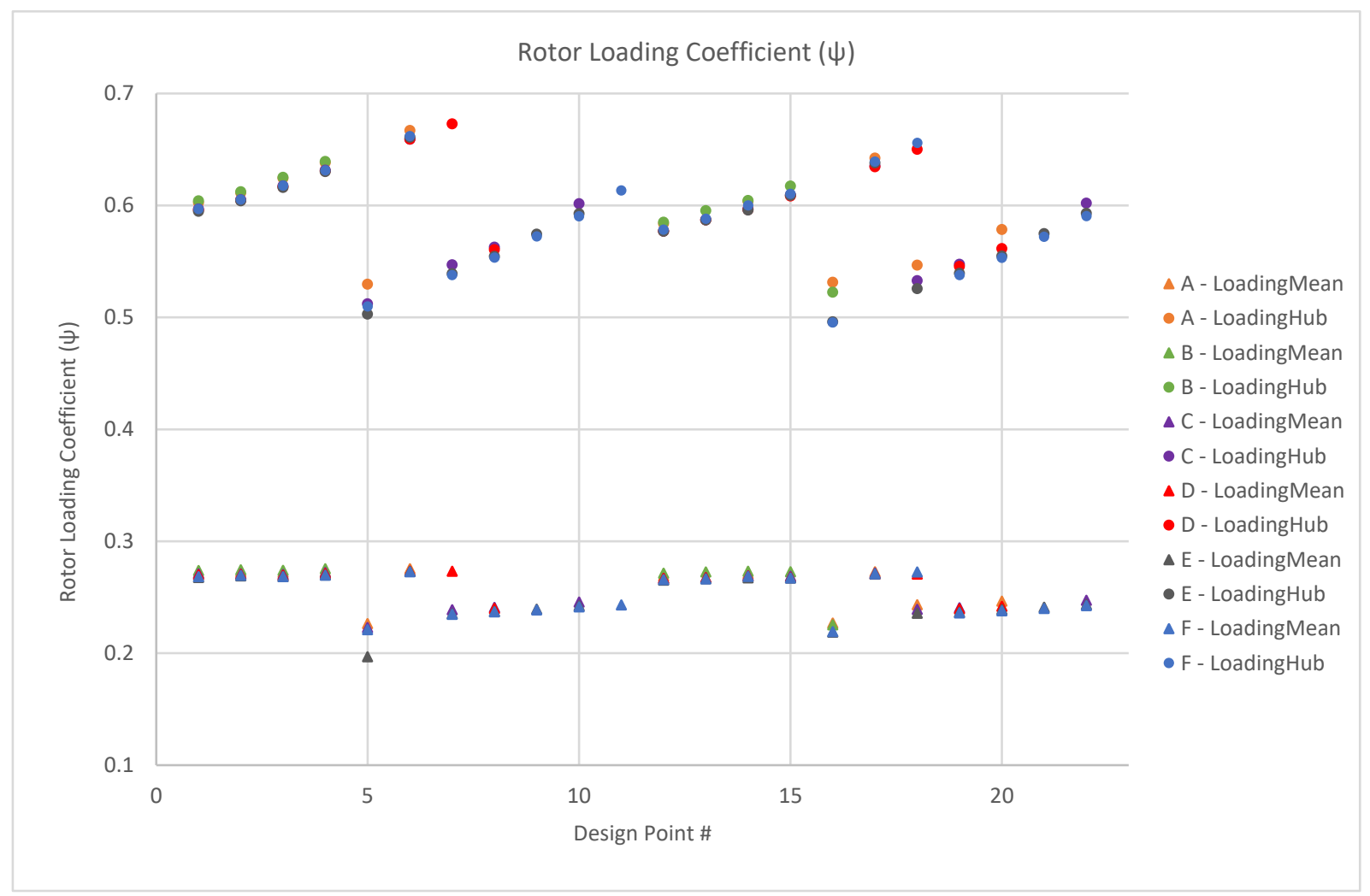

Figure 24. Variations in rotor loading coefficient with different rotor blade parameters

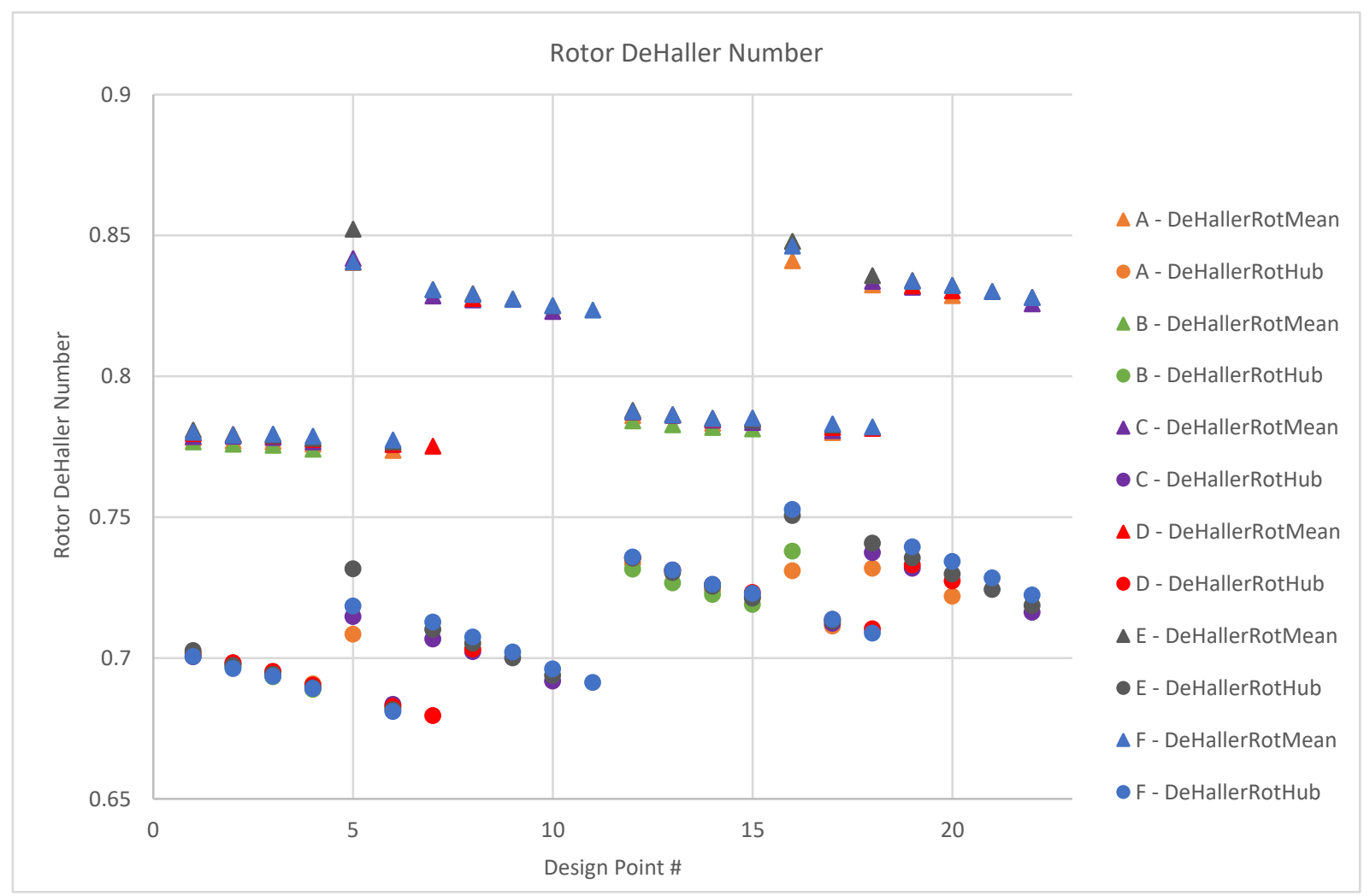

Figure 25. Variations in rotor DeHaller with different rotor blade parameters 


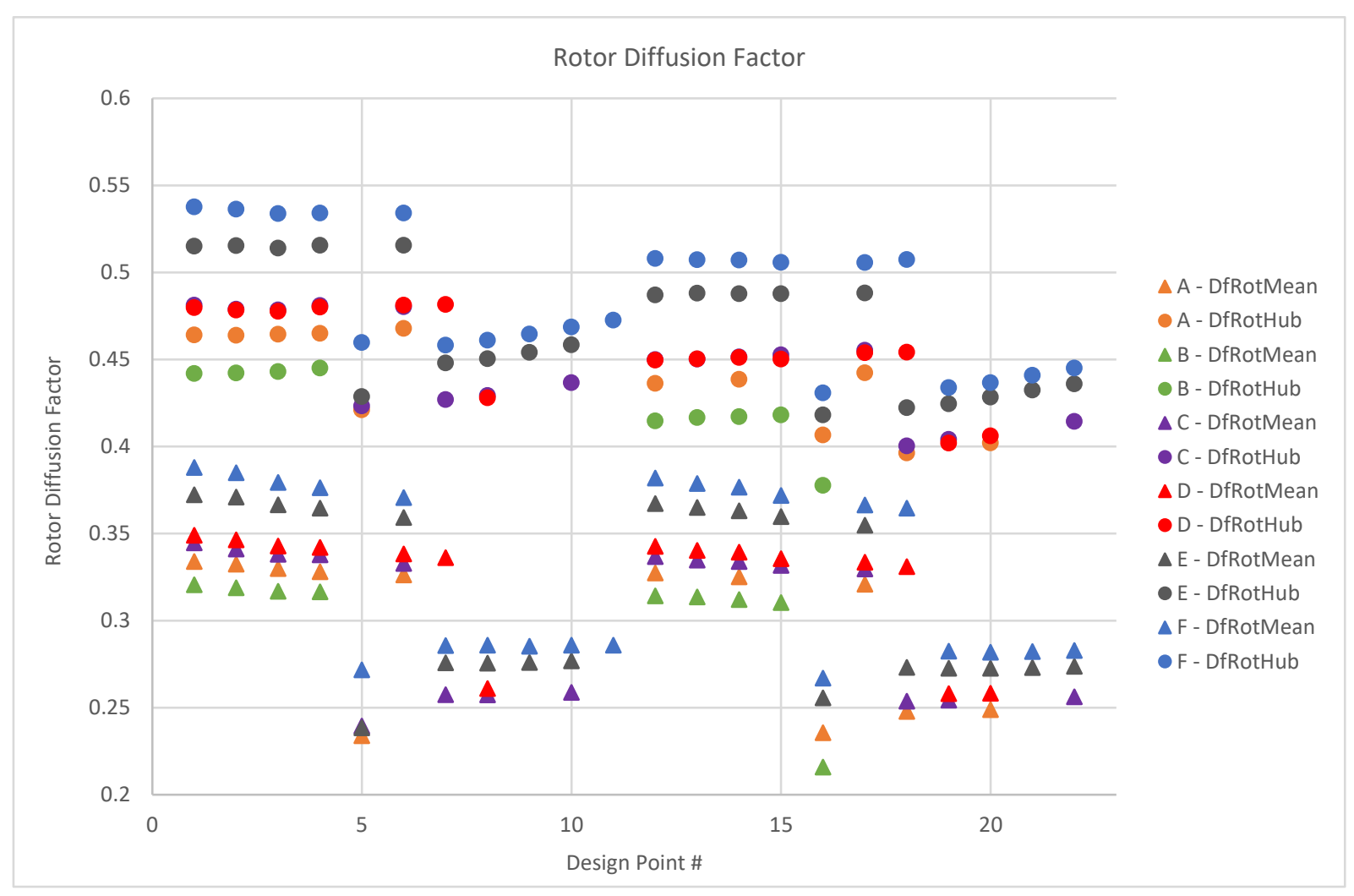

Figure 26. Variations in rotor diffusion factor with different rotor blade parameters

Figure 24 to Figure 26 presents the results of the 2D streamline through flow study for variations in rotor blade parameters. The iteration study (see Table 10Error! Reference source not found.) is performed for varying rotor blade parameters, note that blade aspect ratio $>1.2$ produces failed results and in addition blades become unsuitable dimensions for manufacture. As with $1 \mathrm{D}$ analysis, the rotor loading at the hub increases as the hub-tip ratio decreases, i.e. for fixed annulus the hub dimensions reduce and thus become higher loaded with increase mass flux. The slight increase in hub-tip outlet ratio also follows the same trend of reducing hub loading. The meanline loading in both cases remains light. Similarly, the DeHaller number follows the same trend as with $1 \mathrm{D}$ analysis, whereby $\mathrm{V}_{2} / \mathrm{V}_{1}$ expectedly decreases with the reduced hub-tip ratio. The diffusion factor describes the tendencies for the boundary layer to separate under the influence of the pressure rise in the blade passage and is a good indicator of the blade spacing or pitch to chord ratio s/c. For good efficiency an upper limit of 0.6 for the hub and 0.4-0.45 for the meanline is applied, above 0.5 the associated blading losses exponentially rise. From Figure 33 it is clearly seen that designs with increase trailing edge blade pitch (s), i.e. fewer blades have higher diffusion factors and thus increases blade losses. At the calculated diffusion factors, however, the increased losses are potentially negligible against the benefits of reduced weight and complexity of the design.

Figure 27 and Figure 28 present the results for stator throughflow streamline calculation. Based on the DeHaller number the stator is highly loaded both on the meanline and hub, both due to the high axial velocities with increased rotor swirl and with an introduced ramp on rotor flow path which expectedly increases velocity and loading further downstream in the stator. Higher diffusion factors are satisfactory for the stator with a constraint of $<0.6$, all design points satisfy criteria. 


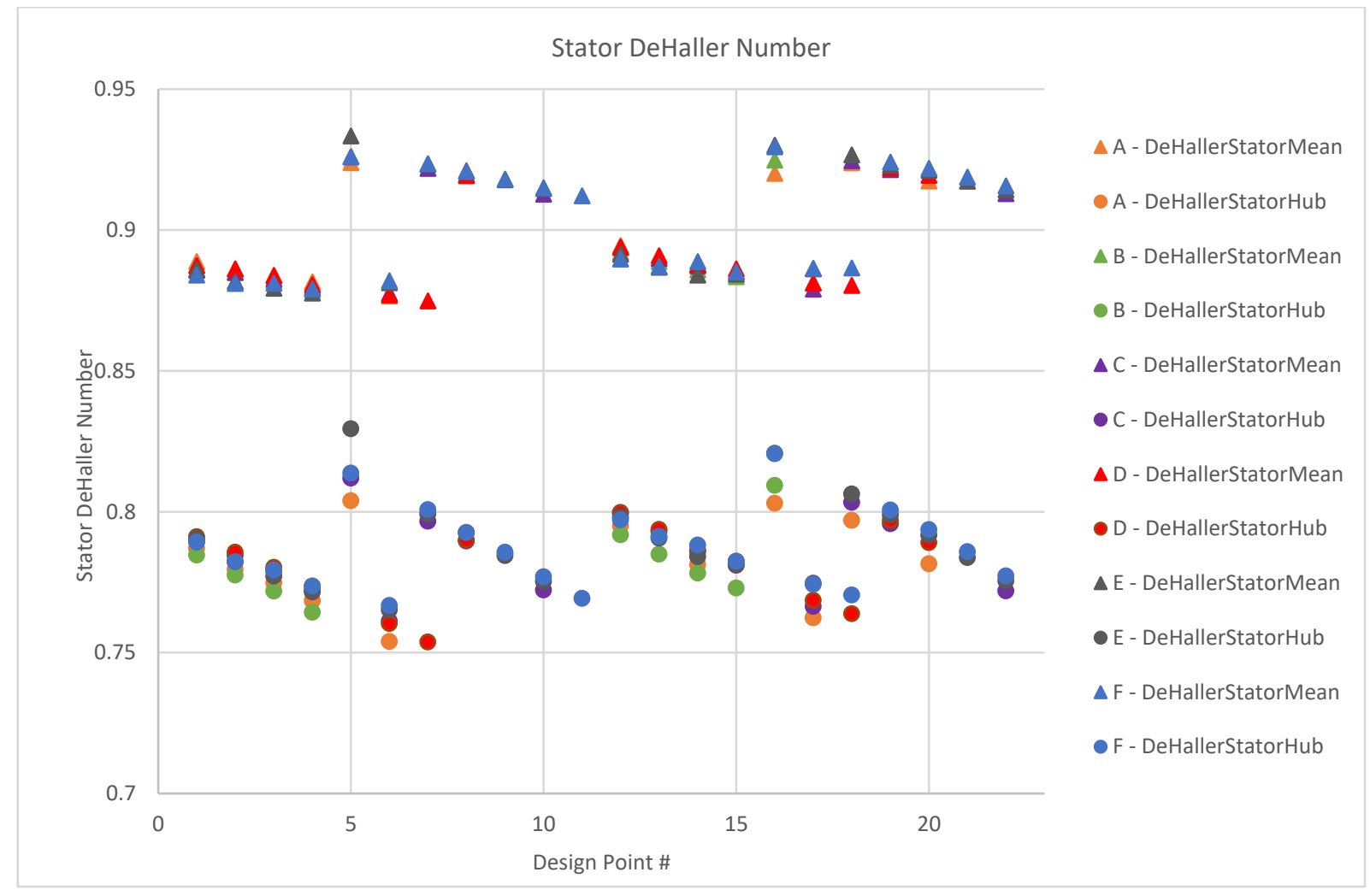

Figure 27. Variations in stator DeHaller factor with different stator blade parameters

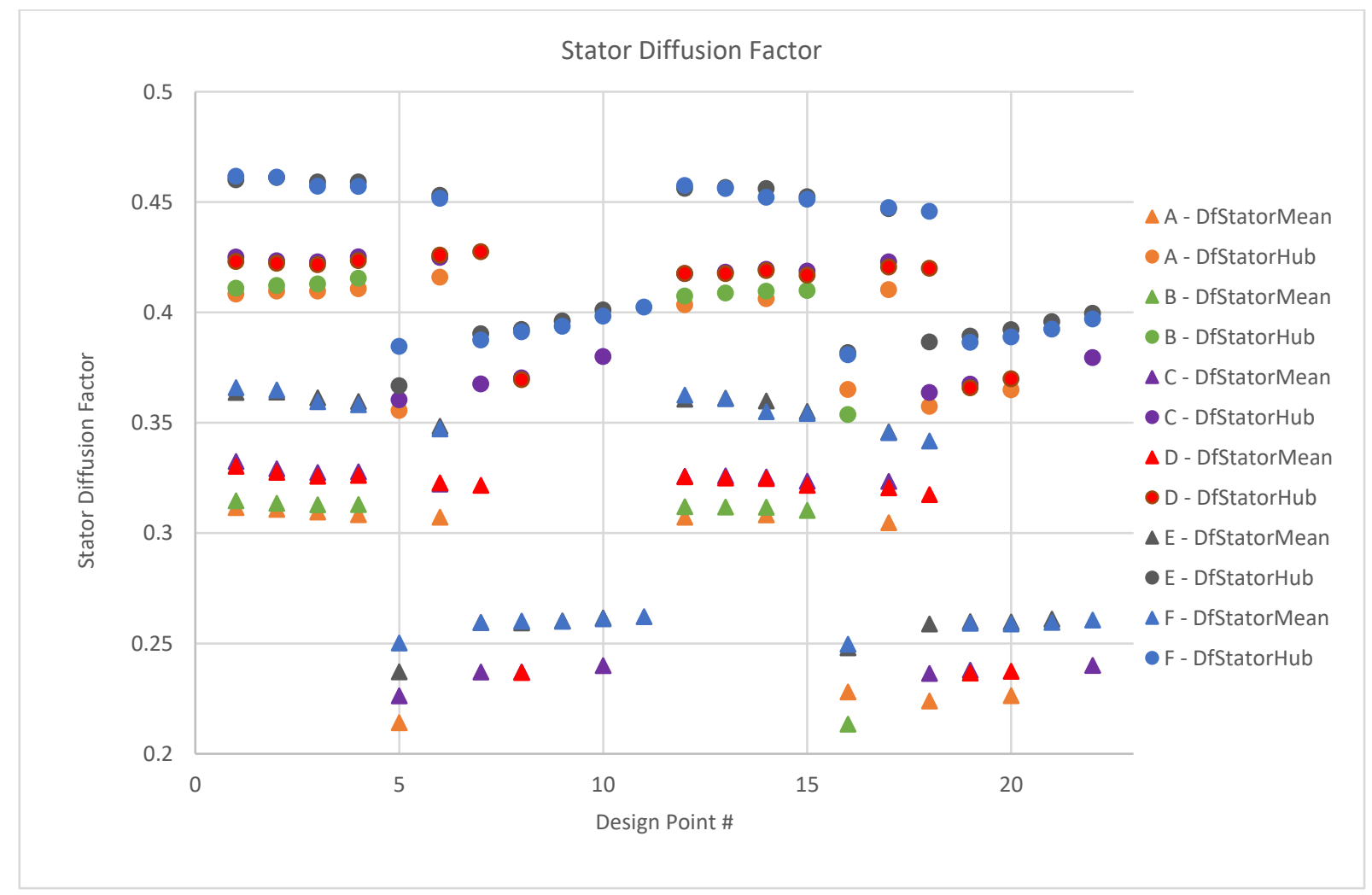

Figure 28. Variations in stator diffusion factor with different stator blade parameters

Design points 5 and $16($ DP5 $=$ HtrInlet $=$ HtrOutlet $=0.56-$ DP16 $=$ HtrInlet $=0.56$, HtrOutlet $=$ 0.57 , respectively) present anomalies in the data pattern for both rotor and stator throughflow analysis. For the rotor, both design points at iteration $\mathrm{E}$ and $\mathrm{F}$ are calculated with reduced hub loading and more favourably diffusion factors. The associated stator design for these points is highly loaded 
at both hub and on meanline, however, investigation into the use of IGV's to reduce stator loading can be conducted in future works. In conclusion of the throughflow analysis, input parameters associated with design points 5 and 6 for iteration $\mathrm{E}$ and $\mathrm{F}$ are chosen for further design evaluation. Preliminary blade geometry for further analysis may also be seen in Figure 29 and Figure 30.

Table 11. Numerical results of chosen design points from throughflow calculation

\begin{tabular}{|c|c|c|c|c|}
\hline \multirow{2}{*}{ Property } & \multicolumn{2}{|c|}{$\mathbf{E}$} & \multicolumn{2}{|c|}{$\mathbf{F}$} \\
\hline & DP 16 & DP 5 & DP 16 & DP 5 \\
\hline \multicolumn{5}{|c|}{ Performance } \\
\hline Power $(\mathrm{kW})$ & 20.737 & 20.437 & 20.545 & 19.370 \\
\hline Torque $(\mathrm{Nm})$ & 6.494 & 6.400 & 6.434 & 6.066 \\
\hline Outlet dynamic pressure (Pa) & 6867.4 & 6639.7 & 6901.2 & 6706.2 \\
\hline Downstream dynamic pressure $(\mathrm{Pa})$ & 3129.9 & 3128.2 & 3145.3 & 3159.6 \\
\hline Aerodynamic efficiency & 0.798 & 0.796 & 0.789 & 0.774 \\
\hline System efficiency $(t-t)$ & 0.644 & 0.653 & 0.650 & 0.689 \\
\hline System efficiency ( $t-s)$ & 0.098 & 0.118 & 0.096 & 0.119 \\
\hline Downstream system efficiency ( $t-s)$ & 0.395 & 0.401 & 0.397 & 0.420 \\
\hline \multicolumn{5}{|c|}{ Rotor } \\
\hline Mean flow coefficient & 0.527 & 0.527 & 0.527 & 0.526 \\
\hline Mean loading & 0.216 & 0.220 & 0.219 & 0.197 \\
\hline Mean DeHaller number & 0.845 & 0.841 & 0.848 & 0.852 \\
\hline Mean deviation & -3 & -3 & -3 & -3 \\
\hline Mean diffusion factor & 0.268 & 0.271 & 0.256 & 0.238 \\
\hline Mean gas exit angle & 20.3 & 20.5 & 20.0 & 18.7 \\
\hline Hub flow coefficient & 0.723 & 0.736 & 0.724 & 0.736 \\
\hline Hub loading & 0.494 & 0.500 & 0.496 & 0.503 \\
\hline Hub DeHaller number & 0.751 & 0.720 & 0.751 & 0.732 \\
\hline Hub deviation & 7.868 & 8.233 & 7.461 & 7.727 \\
\hline Hub diffusion factor & 0.433 & 0.456 & 0.418 & 0.429 \\
\hline Hub gas exit angle & 31.8 & 32.7 & 31.8 & 32.0 \\
\hline \multicolumn{5}{|c|}{ Stator } \\
\hline Mean DeHaller number & 0.925 & 0.926 & 0.930 & 0.933 \\
\hline Mean deviation & 11.073 & 10.954 & 10.055 & 10.465 \\
\hline Mean diffusion factor & 0.274 & 0.278 & 0.248 & 0.237 \\
\hline Mean gas exit angle & 0.96 & 0.23 & 0.22 & -0.75 \\
\hline Hub DeHaller number & 0.822 & 0.818 & 0.821 & 0.829 \\
\hline Hub deviation & 13.494 & 13.240 & 12.782 & 12.749 \\
\hline Hub diffusion factor & 0.395 & 0.397 & 0.382 & 0.367 \\
\hline Hub gas exit angle & 0.61 & 0.14 & 0.13 & -0.42 \\
\hline
\end{tabular}




\begin{tabular}{|c|c|}
\hline Rotor & Stator \\
\hline Blade \& Layer Parameters (using M vs T-Prime & Blade \& Layer Parameters (using M vs T-Prime \\
system) & system) \\
3D Meanline Length $=31.4748$ & 3D Meanline Length $=34.1621$ \\
Camber Length $=31.4748$ & Camber Length $=34.1621$ \\
Cord Length $(\mathrm{C})=31.2338$ & Cord Length $(\mathrm{C})=33.2829$ \\
Meridional Length $(\mathrm{M})=22.9568$ & Meridional Length $(\mathrm{M})=32.7411$ \\
Stagger Angle $=-42.7$ & Stagger Angle $=10.4$ \\
Solidity $(\mathrm{C} / \mathrm{S})=1.02601$ & Solidity $(\mathrm{C} / \mathrm{S})=1.31198$ \\
Pitch Cord Ratio $(\mathrm{S} / \mathrm{C})=0.974649$ & Pitch Cord Ratio $(\mathrm{S} / \mathrm{C})=0.762204$ \\
\hline
\end{tabular}

Figure 29. Preliminary blade parameters

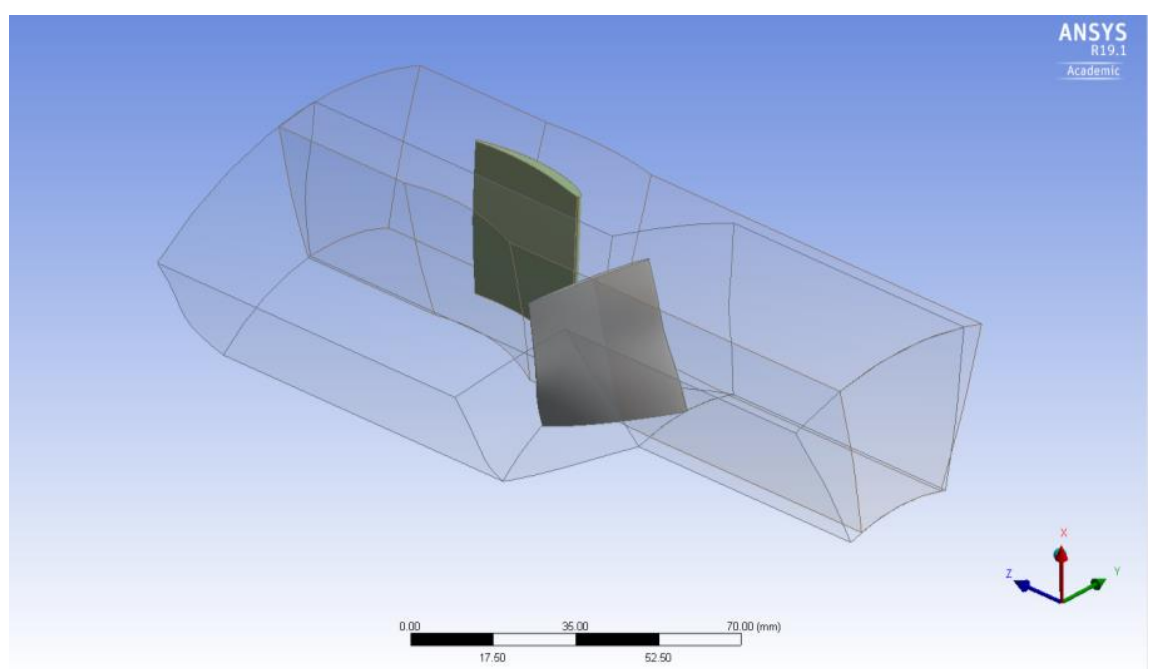

Figure 30. Preliminary view of rotor and stator

\section{Conclusions}

The preliminary objective of this paper was to further investigate the potential application of micro gas turbine propulsion systems for tactical military UAVs through the use of a converted micro-turbojet. It is proposed that with the use of a continuously variable coupling introduced between the fan and an existing micro-turbojet engine, the ability to change gear ratios while maintaining the core running at its optimum enable's operation in a wider gamut of conditions and enhances the performance and scope of tactical UAV missions. The main objective was accomplished by the completion of three separate but dependent design studies for the conversion of micro-turbojet to turbofan. This design methodology is adopted to mimic the similar processes involved in the design of gas turbine propulsion systems in the industry. The results and conclusions of this study are intended to further validate the initial hypothesis that conversion of existing systems while maintaining a simple single spool configuration thus potentially reducing cost and shortening the design process with no changes to the core design provides a more efficient and cost-effective process for the micro gas turbine industry, which inherently have tighter budget constraints for new engine design.

\subsection{Viability of micro turbine engines for tactical military UAVs}

The requirement for microturbine engines for small UAVs is first investigated. It is found that advanced propulsion systems for increased speed and endurance is currently of predominant interest for military applications. From a comprehensive market study, it is found current utilization of MTE's is only found in larger UAV architecture, typical range 3,000-14,000 kg MTOW. This classification of UAV mostly performs the role of intelligence gathering, reconnaissance and communications relay 
platforms and common propulsions systems include those adapted from very light training/business aircraft. From an extensive review of the literature and the markets, it is concluded that currently there is limited application of MTE's in production UAVs under $600 \mathrm{~kg}$, with the majority found in home builds. It is of the author's opinion that small tactical UAVs upgraded MTE propulsion systems can extend on their current role to include, immediate deployment for armed forces on the ground for close recon or strike missions. The speed of such UAVs considering relative size can make detection and interception challenging, and with the continued research of UAV swarming and coordination, has the potential to make small tactical UAVs far more effective than current. In conclusion, considering the success of the Airbus SAGITTA project the evidence suggests that MTE's are an emerging technology with strong applications for tactical UAVs. A technology survey is conducted for currently available micro turbine engines of all configurations. It is noted that there is a significant lack of turbofan and to a certain extent turboprop configurations, to already limited market that consists mainly of turbojet intended for hobbyists. From a comparison study of the ArticShark UAV, a micro turbine turboprop engine was retrofitted to the existing platform in replacement of a more conventional rotary engine. The MTE propulsion system doubled the endurance time of the UAV, due to the overall improved propulsive efficient of gas turbine compared to ICE. It is noted however that a similar comparison study cannot be performed for turbojet or turbofan configurations as most current UAV architecture of the explored MTOW are not designed for transonic flight.

\subsection{Conversion study}

As part of the conversion study, a baseline micro-turbojet is selected so that the performance may be evaluated before and after the proposed conversion. Based on the availability of experimental data, the BMT $120 \mathrm{KS}$ micro-turbojet is selected as the baseline model. Using GasTurb 13 engine performance software the original baseline model is first generated to validate the simulation against experimental and manufacture data. Simulation of the baseline turbojet shows good agreement between data, with the core nominal speed at $120 \mathrm{kRPM}$, a thrust of $130 \mathrm{~N}$ is simulated in comparison to the recorded experimental value of $136.6 \mathrm{~N}$, and simulated fuel mass flow of $0.00472 \mathrm{~kg} / \mathrm{s}$ in comparison to $0.0063 \mathrm{~kg}$.

The converted turbofan engine model is then generated, where the parameters from the baseline model are combined with additional input to form the core stream of the turbofan. A scaled fan performance map from the publicly available NASA quiet engine program is used to evaluate the design point performance of the engine at varying fan operation parameters. In addition, the operation of the fan at varying speeds whilst core remains at optimum through the use of a continuous variable gearbox, thus enabling a single spool platform for simplicity, is studied. It is found that fan operation at close to maximum spool speed yields significantly higher thrust values $180 \mathrm{~N}>130 \mathrm{~N}, 38.46 \%$ increase. Conversely, fan speed operation at 13,068 RPM yields a significant increase in TSFC of $60 \mathrm{~g} /\left(\mathrm{kN}^{*} \mathrm{~s}\right)>36 \mathrm{~g} /\left(\mathrm{kN}^{*} \mathrm{~s}\right), 65.8 \%$ increase. In conclusion, the results show that the converted turbofan has the potential to extend the operating parameters over turbojet for the flight condition of the UAV, dependent on requirements, i.e. increased speed performance for UAV dash, or increased endurance performance with low fuel consumption.

\subsection{Preliminary LPC design}

The preliminary aerodynamic design of the low-pressure compressor to be coupled with studied baseline turbojet is performed. One-dimension meanline and two-dimensional throughflow methods are used to calculate the performance of the compressor at the design point for a variety of input parameters. ANSYS vista is used to rapidly study the performance through iteration of parameters. The comprehensive study is concluded with a set of LPC parameters as seen in Table $\mathbf{1 1}$ to continue the design process in future works.

\subsection{Final Words and Future Work}


In reality, the design process of a new engine and/or individual components involves the collective expertise of many individuals and is a process of continued refinement and optimization. It is hoped that the general conclusions of this study further aid the on-going research for both the application of micro-turbine engines for tactical UAV applications and the potential performance improvement of turbojet micro-turbine engines through a conversion process to turbofan. In addition, the preliminary results of the study for conversion of the BMT $120 \mathrm{KS}$ may be used as the foundation of further design study, with the ultimate goal of manufacture and development of the experimental demonstrator engine. In extension of the work carried out in this paper future work may include.

- $\quad$ LPC preliminary design phase completion. With current data from meanline analysis, a CFD study may be completed and validated against representative model such as the NASA Rotor 37 case as used by [2]. Fan performance maps may then be produced and with HPC/turbine performance maps made available for the BMT $120 \mathrm{KS}$ the off-design performance may be evaluated and primary designs optimized.

- With the use of Advanced Aircraft Analysis software, or other similar types of programmers, the rapid design of a UAV can be conceptualized. The software allows for the rapid estimation of key parameters in the aircraft design with the application of simple equations such as Breguet's range and endurance formula. The propulsion system is specified in the software allowing for a theoretical comparative performance study between an existing UAV platform with turbojet MTE architecture such as the Airbus - Sagitta and proposed converted turbofan MTE.

- Investigation into the use of a continuous variable transmission for the speed requirements is needed, planetary gearbox is suspected to be most feasible solution. Assumed mechanical losses in this study are overestimated, thus if a more efficient gearbox can be investigated and evaluated, the performance of the converted turbofan will subsequently increase. 


\section{Appendix A}

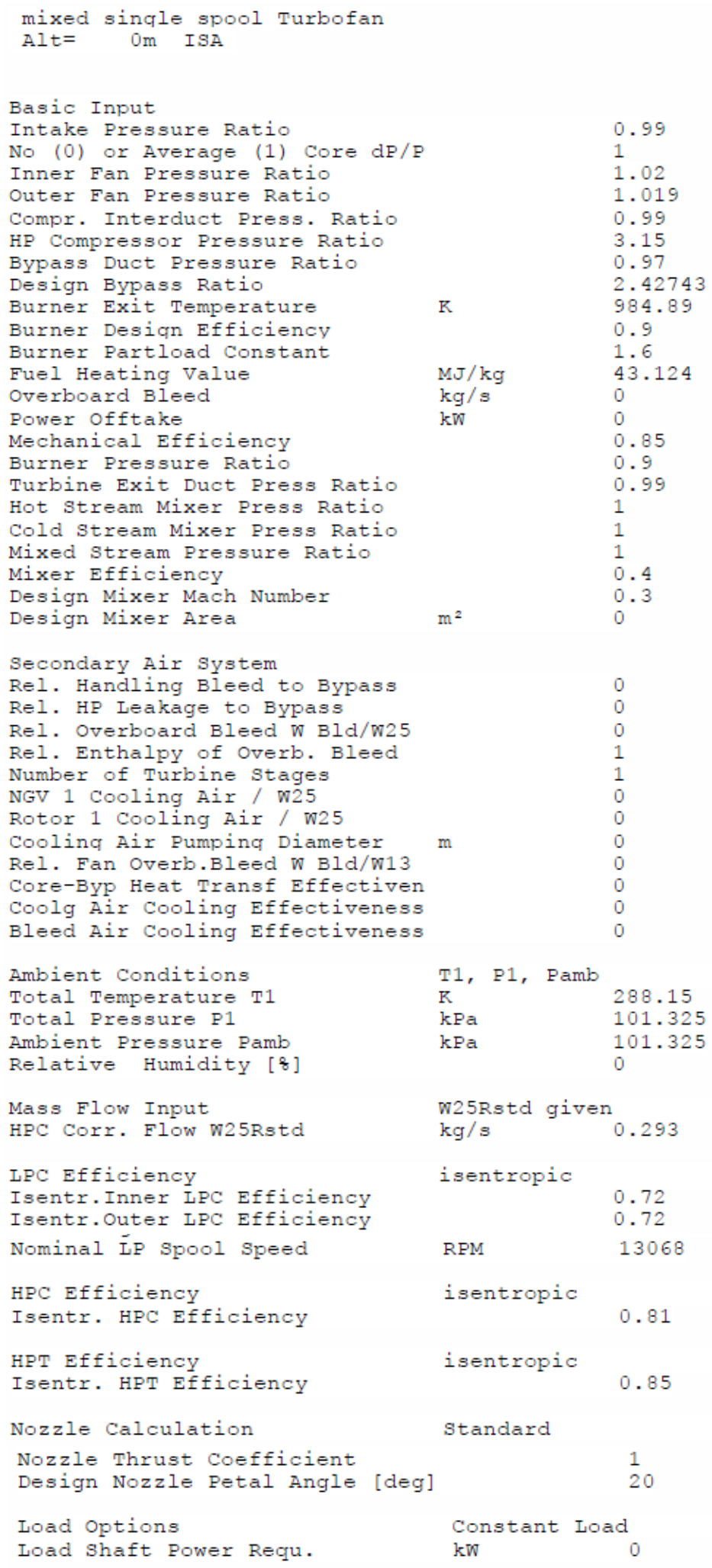

$\begin{array}{ll} & 0.99 \\ 1 & 1.02 \\ & 1.019 \\ & 0.99 \\ & 3.15 \\ & 0.97 \\ & 2.42743 \\ & 984.89 \\ \mathrm{k} & 0.9 \\ & 1.6 \\ \mathrm{MJ} / \mathrm{kg} & 43.124 \\ \mathrm{~kg} / \mathrm{s} & 0 \\ \mathrm{~kW} & 0 \\ & 0.85 \\ & 0.9 \\ & 0.99 \\ & 1 \\ & 1 \\ \mathrm{~m} 2 & 1 \\ & 0.4 \\ & 0.3\end{array}$

$\begin{array}{ll} & 0 \\ & 0 \\ & 0 \\ & 1 \\ & 1 \\ & 0 \\ & 0 \\ \mathrm{~m} & 0 \\ & 0 \\ & 0 \\ \mathrm{~T} 1, \mathrm{P} 1, \quad \mathrm{Pamb} & \\ \mathrm{K} & 0 \\ \mathrm{kPa} & 288.15 \\ \mathrm{kPa} & 101.325 \\ & 101.325 \\ & 0\end{array}$

Figure 31 GasTurb Turbofan Engine Model Input Parameters - Fan @ 13,068 RPM 


\begin{tabular}{|c|c|c|}
\hline \multicolumn{3}{|l|}{ Basic Input } \\
\hline Intake Pressure Ratio & & 0.99 \\
\hline No (0) or Average (1) Core dP/P & & 1 \\
\hline Inner Fan Pressure Ratio & & 1.04 \\
\hline Outer Fan Pressure Ratio & & 1.035 \\
\hline Compr. Interduct Press. Ratio & & 0.99 \\
\hline HP Compressor Pressure Ratio & & 3.15 \\
\hline Bypass Duct Pressure Ratio & & 0.97 \\
\hline Design Bypass Ratio & & 4.0578 \\
\hline Burner Exit Temperature & $\mathrm{K}$ & 984.89 \\
\hline Burner Design Efficiency & & 0.9 \\
\hline Burner Partload Constant & & 1.6 \\
\hline Fuel Heating Value & $\mathrm{MJ} / \mathrm{kg}$ & 43.124 \\
\hline Overboard Bleed & $\mathrm{kg} / \mathrm{s}$ & 0 \\
\hline Power offtake & $\mathrm{kW}$ & 0 \\
\hline Mechanical Efficiency & & 0.87 \\
\hline Burner Pressure Ratio & & 0.9 \\
\hline Turbine Exit Duct Press Ratio & & 0.99 \\
\hline Hot Stream Mixer Press Ratio & & 1 \\
\hline Cold Stream Mixer Press Ratio & & 1 \\
\hline Mixed Stream Pressure Ratio & & 1 \\
\hline Mixer Efficiency & & 0.4 \\
\hline Design Mixer Mach Number & & 0.3 \\
\hline Design Mixer Area & $\mathrm{m}^{2}$ & 0 \\
\hline Secondary Air System & & \\
\hline Rel. Handling Bleed to Bypass & & 0 \\
\hline Rel. HP Leakage to Bypass & & 0 \\
\hline Rel. Overboard Bleed $\mathrm{W} \mathrm{Bld} / \mathrm{W} 25$ & & 0 \\
\hline Rel. Enthalpy of Overb. Bleed & & 1 \\
\hline Number of Turbine Stages & & 1 \\
\hline NGV 1 Cooling Air / W25 & & 0 \\
\hline Rotor 1 Cooling Air / w25 & & 0 \\
\hline Cooling Air Pumping Diameter & $\mathrm{m}$ & 0 \\
\hline Rel. Fan Overb.Bleed $\mathrm{W}$ Bld/W13 & & 0 \\
\hline Core-Byp Heat Transf Effectiven & & 0 \\
\hline Coolg Air Cooling Effectiveness & & 0 \\
\hline Bleed Air Cooling Effectiveness & & 0 \\
\hline Ambient Conditions & T1, P1, Pamb & \\
\hline Total Temperature $\mathrm{T} 1$ & & 288.15 \\
\hline Total Pressure P1 & $\mathrm{kPa}$ & 101.325 \\
\hline Ambient Pressure Pamb & $\mathrm{kPa}$ & 101.325 \\
\hline Relative Humidity [\&] & & 0 \\
\hline Mass Flow Input & W25Rstd given & \\
\hline HPC Corr. Flow w25Rstd & $\mathrm{kg} / \mathrm{s}$ & 0.293 \\
\hline LPC Efficiency & isentropic & \\
\hline Isentr.Inner IPC Efficiency & & 0.8 \\
\hline Isentr.Outer LPC Efficiency & & 0.78 \\
\hline Nominal L̈P Spool Speed & RPM & 21780 \\
\hline HPC Efficiency & isentropic & \\
\hline Isentr. HPC Efficiency & & 0.81 \\
\hline HPT Efficiency & isentropic & \\
\hline Isentr. HPT Efficiency & & 0.85 \\
\hline Nozzle Calculation & Standard & \\
\hline Nozzle Thrust Coefficient & & 1 \\
\hline Design Nozzle Petal Angle [deg] & & 20 \\
\hline Load Options & Constant Load & \\
\hline Load Shaft Power Requ. & $\mathrm{kW}$ & 0 \\
\hline
\end{tabular}

Figure 32 GasTurb Turbofan Engine Model Input Parameters - Fan @ 21,780 RPM 


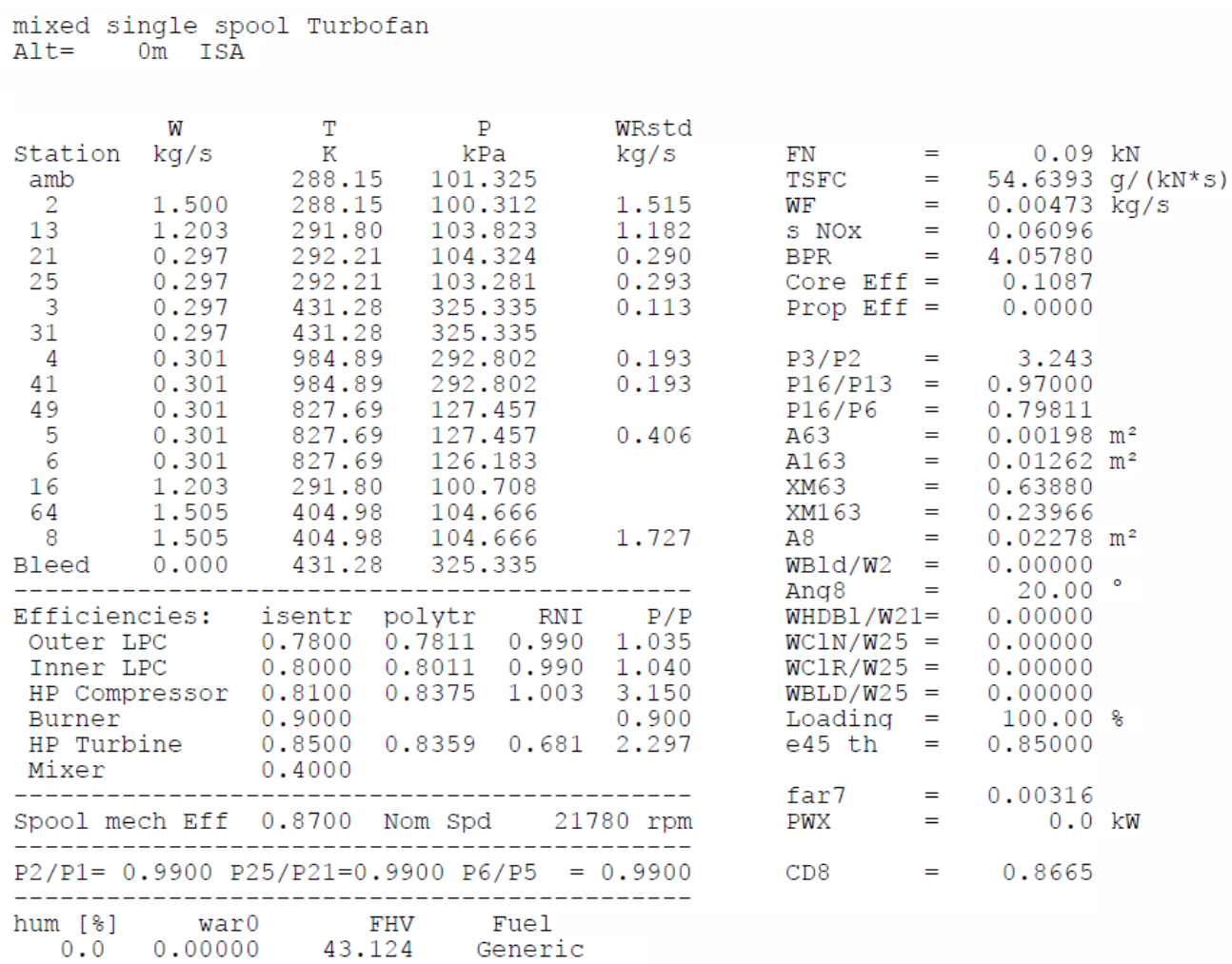

Figure 33 GasTurb simulation results for fan speed 21,780 RPM

\begin{tabular}{|c|c|c|c|c|c|}
\hline & W & $\mathrm{T}$ & P & & WRstd \\
\hline $\begin{array}{c}\text { Station } \\
\text { amb }\end{array}$ & $\mathrm{kg} / \mathrm{s}$ & $\begin{array}{c}\mathrm{K} \\
288.15\end{array}$ & $\begin{array}{r}\mathrm{kP} \\
101 .\end{array}$ & $\begin{array}{l}a \\
325\end{array}$ & $\mathrm{~kg} / \mathrm{s}$ \\
\hline 2 & 1.000 & 288.15 & 100. & 312 & 1.010 \\
\hline 13 & 0.708 & 290.31 & 102. & 218 & 0.705 \\
\hline 21 & 0.292 & 290.42 & 102. & 318 & 0.290 \\
\hline 25 & 0.292 & 290.42 & 101. & 295 & 0.293 \\
\hline 3 & 0.292 & 428.68 & 319. & 079 & 0.113 \\
\hline 31 & 0.292 & 428.68 & 319. & 079 & \\
\hline 4 & 0.296 & 984.89 & 287. & 171 & 0.193 \\
\hline 41 & 0.296 & 984.89 & 287. & 171 & 0.193 \\
\hline 49 & 0.296 & 836.49 & 131. & 520 & \\
\hline 5 & 0.296 & 836.48 & 131. & 520 & 0.389 \\
\hline 6 & 0.296 & 836.48 & 130. & 204 & \\
\hline 16 & 0.708 & 290.31 & 99. & 151 & \\
\hline 64 & 1.005 & 459.51 & 105. & 774 & \\
\hline 8 & 1.005 & 459.51 & 105. & 774 & 1.215 \\
\hline Bleed & 0.000 & 428.68 & 319. & 079 & \\
\hline Efficier & ies: & isentr & polytr & RNI & $P / P$ \\
\hline Outer I & & 0.7200 & 0.7207 & 0.990 & 1.019 \\
\hline Inner I & & 0.7200 & 0.7208 & 0.990 & 1.020 \\
\hline $\mathrm{HP}$ Comr & ressor & 0.8100 & 0.8375 & 0.990 & 3.150 \\
\hline Burner & & 0.9000 & & & 0.900 \\
\hline HP Turb & ne & 0.8500 & 0.8368 & 0.668 & 2.183 \\
\hline Mixer & & & & & \\
\hline spool me & h Eff & 0.8500 & Nom Spd & 13 & $68 \mathrm{rp}$ \\
\hline $\mathrm{P} 2 / \mathrm{P} 1=$ & $9900 \mathrm{~B}$ & $5 / \mathrm{P} 21=0$. & $9900 \quad \mathrm{P} 6$ & P5 $=$ & 0.990 \\
\hline $\begin{array}{c}\text { hum }\left[\frac{8}{6}\right] \\
0.0\end{array}$ & & & $\mathrm{HV}$ & Euel & \\
\hline 0.0 & 0.0000 & & 24 & eneric & \\
\hline
\end{tabular}

\begin{tabular}{|c|c|c|c|}
\hline EN & $=$ & 0.08 & $\mathrm{kN}$ \\
\hline TSFC & $=$ & 60.0880 & $\mathrm{~g} /\left(\mathrm{kN}^{*} \mathrm{~s}\right)$ \\
\hline WF & $=$ & 0.00468 & $\mathrm{~kg} / \mathrm{s}$ \\
\hline$s$ NOX & $=$ & 0.05969 & \\
\hline BPR & $=$ & 2.42743 & \\
\hline Core Eff & $=$ & 0.1004 & \\
\hline Prop Eff & $=$ & 0.0000 & \\
\hline P3/P2 & $=$ & 3.181 & \\
\hline P16/P13 & $=$ & 0.97000 & \\
\hline P16/P6 & $=$ & 0.76150 & \\
\hline A 63 & $=$ & 0.00183 & $m^{2}$ \\
\hline A1 63 & $=$ & 0.00846 & $m^{2}$ \\
\hline XM63 & $=$ & 0.68482 & \\
\hline XM1 63 & $=$ & 0.21147 & \\
\hline A 8 & $=$ & 0.01401 & $m^{2}$ \\
\hline WB1d/W2 & $=$ & 0.00000 & \\
\hline Ang 8 & $=$ & 20.00 & $\circ$ \\
\hline WHDBl/W21 & $=$ & 0.00000 & \\
\hline WC1N/W25 & $=$ & 0.00000 & \\
\hline WC1R/W25 & $=$ & 0.00000 & \\
\hline WBLD /W2 5 & $=$ & 0.00000 & \\
\hline Loading & $=$ & 100.00 & 8 \\
\hline e45 th & $=$ & 0.85000 & \\
\hline $\operatorname{far} 7$ & $=$ & 0.00468 & \\
\hline PWX & $=$ & 0.0 & $\mathrm{~kW}$ \\
\hline CD8 & $=$ & 0.8686 & \\
\hline
\end{tabular}

Figure 34 GasTurb simulation results for fan speed 13,068 RPM 


\section{References}

[1] B. Cukurel and K. Kadosh, "Micro-Turbojet to Turbofan Conversion Via Continuously Variable Transmission: Thermodynamic Performance Study," Journal of Engineering for Gas Turbines And Power 139, 2016.

[2] M. İlhan, M. Gürbüz and S. Acarer, "Aerodynamic Design Investigation Of HPT-Driven Low-Pressure Compression System for Variable-Speed Micro UAV Engine," Proceedings of ASME Turbo Expo 2018: Turbine Technical Conference and Exposition GT2018-76677, 2018.

[3] Ministry of Defence and Military Aviation Authority, Regulatory Article (RA) 1600: remotely piloted air systems (RPAS), 2015.

[4] C. Soares, Microturbines Applications for Distributed Energy Systems, Amsterdam: Elsevier/ButterworthHeinemann, 2007.

[5] J. R. Nelson and D. M. Dix, "Development of Engines for Unmanned Air Vehicles: Some Factors to be Considered," Institute for Defense Analyses, Alexandria, VA, 2003.

[6] D. S. Kringe, "Performance Evaluation of a Micro Gas Turbine Centrifugal Compressor Diffuser," Masters Thesis, Faculty of Mechanical and Mechatronic Engineering at Stellenbosch University, 2013.

[7] C. Burger, Design Procedure of a Compact Aerodynamic Crossover Diffuser, Stellenbosch University, 2016.

[8] F. Oppong, Micro Gas Turbine Performance Evaluation, Faculty of Engineering at Stellenbosch University, 2016.

[9] F. V. Smit, "Investigating the design of the turbine stage of a specific micro-gas turbine engine," Stellenbosch University, 2014.

[10] R. Giffin, D. Parker and L. Dunbar, “Experimental Quiet Engine Program Aerodynamic Perfromance of Fan A, Report No. NASA CR 120858," NASA, Washington , 1971.

[11] The Development, Concepts and Doctrine Centre, "Joint Doctrine Publication 0-30.2 Unmanned Aircraft Systems," Ministry of Defense, Swindon, 2017.

[12] Baird Micro Turbines, "Operators Manual for the BMT120KS Series Turbine Engine," Baird Micro Turbines (Pty) Ltd., Panorama, South Africa, n.d..

[13] C. L. Barend de Villiers, "Design of a Centrifugal Compressor for Application in Micro Gas Turbines," Master of Engineering Degree, Faculty of Engineering at Stellenbosch University, 2014. 